\title{
Deciphering the link between PI3K and PAK: An opportunity to target key pathways in pancreatic cancer?
}

\author{
Kiruthikah Thillai ${ }^{1,2, *}$, Hoyin Lam ${ }^{1, *}$, Debashis Sarker ${ }^{1,2}$ and Claire M. Wells ${ }^{1}$ \\ ${ }^{1}$ Division of Cancer Studies, King's College London, London, United Kingdom \\ 2 Department of Medical Oncology, Guy's and St Thomas' NHS Trust, London, United Kingdom \\ *Both authors have contributed equally to this work \\ Correspondence to: Claire M. Wells, email: claire.wells@kcl.ac.uk \\ Keywords: pancreatic cancer, PAK, PI3K
}

Received: July 29, $2016 \quad$ Accepted: October 27, 2016

Published: November 11, 2016

\section{ABSTRACT}

The development of personalised therapies has ushered in a new and exciting era of cancer treatment for a variety of solid malignancies. Yet pancreatic ductal adenocarcinoma (PDAC) has failed to benefit from this paradigm shift, remaining notoriously refractory to targeted therapies. Chemotherapy is the cornerstone of management but can offer only modest survival benefits of a few months with 5-year survival rates rarely exceeding $3 \%$. Despite these disappointing statistics, significant strides have been made towards understanding the complex biology of pancreatic cancer, with deep genomic sequencing identifying novel genetic aberrations and key signalling pathways. The PI3K-PDK1-AKT pathway has received great attention due to its prominence in carcinogenesis. However, efforts to target several components of this network have resulted in only a handful of drugs demonstrating any survival benefit in solid tumors; despite promising pre-clinical results. p-21 activated kinase 4 (PAK4) is a gene that is recurrently amplified or overexpressed in PDAC and both PAK4 and related family member PAK1, have been linked to aberrant RAS activity, a common feature in pancreatic cancer. As regulators of PI3K, PAKs have been highlighted as a potential prognostic marker and therapeutic target. In this review, we discuss the biology of pancreatic cancer and the close interaction between PAKs and the PI3K pathway. We also suggest proposals for future research that may see the development of effective targeted therapies that could finally improve outcomes for this disease.

\section{INTRODUCTION TO PANCREATIC DUCTAL ADENOCARCINOMA (PDAC)}

Pancreatic ductal adenocarcinoma (PDAC) is a devastating and lethal disease. Epidemiological trends predict that over the next two decades PDAC will overtake breast, colorectal and prostate cancer to become the second leading cause of cancer related mortality worldwide [1]. Due to the surreptitious nature of PDAC formation, the majority of patients present with advanced disease that is inoperable and therefore incurable. Even those few that undergo surgery are likely to succumb to metastatic spread within two years. Despite significant international research efforts, the last twenty years have witnessed the development of only two new chemotherapy regimens, both of which fail to improve survival by more than a few months for advanced disease compared with the previous standard of care, the nucleoside analogue gemcitabine $[2$, 3]. To date, there are no effective targeted therapies for PDAC, highlighting the need for a better understanding of pancreatic tumor biology and the identification of new exploitable pathways.

By far the most common malignancy to arise from the pancreas, PDAC is a heterogeneous genetic disease with over 60 mutations identified per tumor [4]. Despite this, PDACs have several distinctive features; characteristic mutations in established onco- and tumor suppressor genes, dense surrounding stromal tissue and a high propensity to metastasize [5-7]. PDACs typically arise from one of three histological precursor lesions; pancreatic intra-epithelial neoplasia (PanIN), intra ductal papillary mucinous neoplasm (IPMN) and 
mucinous cystic neoplasia [8]. Echoing the behavior of other adenocarcinomas, pancreatic cancer develops in a stepwise fashion from low- to high-grade dysplasia before culminating in malignant transformation [9, 10]. This process is accompanied by an increasing frequency of genetic aberrations [11]. The commonest mutation is at codon 12 in the proto-oncogene Kristen rat sarcoma viral oncogene homolog $(K R A S)$ [12]. Responsible for encoding a small $(\sim 21 \mathrm{kDa})$ GTPase, KRAS mutations occur in nearly $100 \%$ of PDAC tumors [12]. Often the first gene to be mutated in PDAC, it has also been recurrently identified in pre-invasive lesions and is therefore thought to be involved in carcinogenesis [13-16]. Constitutive activation of KRAS results in sustained and unregulated proliferation, evasion of apoptosis, re-modelling of the micro-tumor environment, increased cell migration and metastatic spread [17-20]. Murine pancreata with KRAS G12D or $K R A S^{G 12 V}$ mutations invariably develop dysplastic changes and subsequent invasive metastatic PDAC [16]. Three further genetic aberrations commonly occur in PDAC, namely inactivation of $p 16 I N K 4 A / C D K N 2 A$ (p16), Tp53 and $S M A D$ family member $4(S M A D 4)$ with a reported prevalence of $50-70 \%, 55 \%$ and $10 \%$ respectively in invasive PDAC $[15,21]$. Whilst nearly $90 \%$ of precursor PanIN lesions harbor a $K R A S$ mutation, these three 'loss of function' aberrations are less prevalent in pre-cancerous pathology compared with cancer samples, suggesting they occur later in oncogenesis.

Extensive exome sequencing and copy number analyses of 142 early-stage PDAC samples have led to a clearer portrayal of the genomic landscape [14]. 16 genes were found to be recurrently mutated. In addition to established mutations, several genes responsible for modifying chromatic and DNA damage repair were also mutated. Further aberrations in the SLIT/ROBO signaling pathway were identified, implicating axon guidance genes in pancreatic cancer development. A more recent genomic analysis of 456 early stage PDAC samples identified 32 genes that were recurrently mutated, each of which could be assigned to 10 pathways; KRAS, TGF- $\beta$, WNT, NOTCH, ROBO/SLIT signaling, G1/S transition, SWI-SNF, chromatin modification, DNA repair and RNA processing [22]. Expression analysis led to the classification of 4 subtypes; squamous, pancreatic progenitor, immunogenic and aberrantly differentiated endocrine and exocrine (ADEX) with clear correlation of histological features.

Whilst it is now clear that PDAC is a complex genetic disease developing from a cascade of mutations in pancreatic cells, this knowledge has yet to have a meaningful clinical impact on PDAC survival. Nevertheless, the identification of key pathways is vital in guiding the search for novel therapeutic targets as well as potential prognostic and predictive biomarkers. A pilot study of 92 patients assessed the feasibility of attaining PDAC tissue for genomic analysis in 'real-time' in order to perform genetic screening within a clinically satisfactory time-frame [23]. Three molecular targets were screened for: HER2 amplification, $K R A S$ wild type and mutations in DNA damage repair pathway (BRCA1, $B R C A 2, P A L B 2$ and ATM). 22 patients with these genetic signatures were identified. The study highlighted the potential for personalized therapy using high-quality actionable genomic data but demonstrated the challenges of efficiently screening bio specimens in these patients as well as the need for improved clinical trial options.

\section{THE PHOSPHATIDYLINOSITIDE 3- KINASE (PI3K) FAMILY}

Oncogenic KRAS activates a plethora of effector downstream pathways. The two most significant canonical signaling pathways are mitogen activated protein kinase (MAPK) (see review by Samatar et al for a more detailed description of the MAPK pathway) and the phosphatidylinositide 3-kinase (PI3K) pathway [24]. The PI3K-PDK1-AKT pathway is an intricate signaling network, regulating cell metabolism, growth, migration, survival and angiogenesis and therefore when aberrantly activated, results in oncogenesis [25]. The PI3K family is a group of lipid kinases that phosphorylates the 3 ' $\mathrm{OH}$ group of phosphatidylinositols [26]. There are three classes, each distinguished by structural and functional differences. Class 1 PI3Ks are the best characterized in cancer and primarily responsible for the production of D-3 phosphoinositides in response to various growth factors, and it is against this class that drug development efforts to target this pathway have focused on $[27,28]$.

\section{PI3K signaling}

Each class $1 \mathrm{~A}$ PI3K protein contains both a regulatory- (p85) and catalytic-(p110) subunit. p85 has 3 isoforms p $85 \alpha$ (p85 $\alpha, \mathrm{p} 55 \alpha$ and $\mathrm{p} 50 \alpha), \mathrm{p} 86 \alpha$ and $\mathrm{p} 55 \gamma$ each encoded by three genes, PIK3R1, PIK3R2 and $P I K 3 R 3$ respectively [29]. The catalytic subunit also has 3 isoforms (p110 $\alpha, \mathrm{p} 110 \beta$ and $\mathrm{p} 110 \delta)$ encoded by PIK3CA, $P I K 3 C B$ and $P I K 3 C D$ respectively (Figure 1). It is the regulatory subunit that maintains the catalytic subunit in its less active state in quiescent cells and interacts with phosphotyrosine residues of adaptor proteins or activated growth factor receptors [27]. Somatic mutations of the aforementioned genes can lead to constitutive activation of the PI3K pathway and subsequent malignant transformation of cells [30]. In the absence of mutation, amplification of PIK3CA has also been identified as a driver in a number of epithelial tumors [31, 32]. Once activated, PI3K converts the lipid phospatidylinsotide4,5-bisphophate $\left(\mathrm{PIP}_{2}\right)$ to phosphatidylinositide 3,4,5triphosphate $\mathrm{PIP}_{3}$ (Figure 2). Proteins with pleckstring homology $(\mathrm{PH})$ domains travel to the sites of PI3K 
activation and bind to $\mathrm{PIP}_{3}$. Two specific serine/threonine kinases PDK1 and AKT are subsequently both brought into close proximity of each other by $\mathrm{PIP}_{3}[27]$. PDK1 activates AKT by phosphorylation of the threonine site (T308) in AKT. The serine site (S473) can be activated by several kinases including mTOR complex 2 (mTORC2), PDK-1, integrin-linked kinase (ILK) and AKT itself [3335].

This critical signal between PDK1 and AKT promotes cell growth and survival by various mechanisms including the inhibition of the pro-apoptotic factors $\mathrm{BAD}$ and BAX [36]. One of the major downstream effectors of AKT is mTOR complex 1 (mTORC1) which is responsible for growth factor signaling, AMP levels, oxygen availability and nutrition [37]. The tumor suppressor gene phosphatase and tensin homolog deleted on chromosome 10 (PTEN) dephosphorylates PIP3, converting it back to $\mathrm{PIP}_{2}$, subsequently terminating this process and is therefore a critical negative regulator of the PI3K pathway. Arguably the most important tumor suppressor gene second only to p53 in many malignancies, loss of PTEN activity can result from mutation, promoter methylation, phosphorylation or delocalization from the plasma membrane [38].

Although there is clear evidence implicating Class 1A PI3Ks in PDAC oncogenesis, Class 1B has also

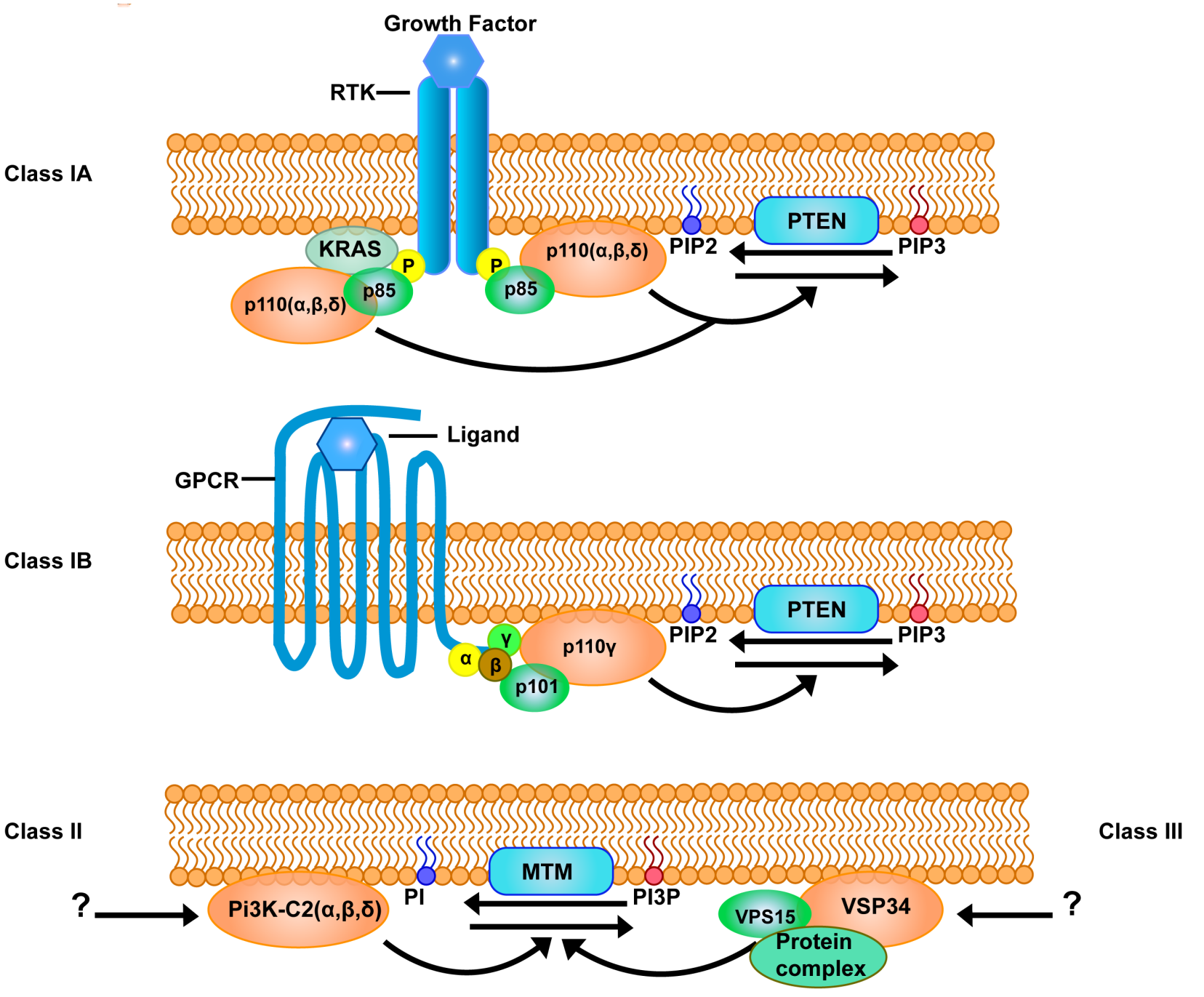

Figure 1: Different classes of the PI3K family. The phosphatidylinositol 3-kinase (PI3K) family comprises of three classes with several isoforms which catalyses different substrates. Class I PI3K consists of Class IA and Class IB Pi3Ks, both converting phosphatidylinositide 4,5- bisphosphate (PIP2) into phosphatidylinositide 3,4,5- triphosphate (PIP3). Class IA PI3Ks are activated by receptor tyrosine kinases (RTK) which can activate catalytic isoforms $\mathrm{p} 110 \alpha, \beta$ and $\delta$ through the adaptor subunit $\mathrm{p} 85$. There are five known adaptor subunit isoforms, namely $\mathrm{p} 85 \alpha, \mathrm{p} 85 \beta, \mathrm{p} 55 \alpha, \mathrm{p} 55 \gamma$ and $\mathrm{p} 50 \alpha$. Class IB PI3K are activated by G-protein coupled receptors (GPCRs) and has one catalytic subunit p110 $\gamma$ and two known regulatory subunits p101 and p87. Phosphatase and tensin homolog (PTEN) phosphatase inactivates Class I PI3K signaling. Class II and class III PI3Ks are known to catalyze phosphatidylinositol (PI) into phosphatidylinositol 3-phosphate (PI3P). Myotubularin (MTM) phosphatase inactivates both class II and class III PI3K signaling. Class II PI3Ks consists of a catalytic subunit with three isoforms PI3K-C2 $\alpha, \beta$, and $\gamma$, but does not associate with any regulatory subunits. Class III PI3K is composed of a VPS32 catalytic subunit and a VPS15 regulatory subunit, often bound in a multiprotein complex. 
been implicated in tumor formation. Indeed, P110r is expressed in patients with pancreatitis suggesting it has a role in inflammation, which in turn is thought to be a precursor for malignancy. Pre-clinical kinetic assays have determined that $\mathrm{p} 110 \beta$ and $\Upsilon$ are required for AKT activation [39].

\section{PI3K pathway in PDAC}

The PI3K pathway appears to be critical in the development and maintenance of PDAC. In a recent study of transgenic mice with $K R A S^{G 12 D}$ mutations, PDK1 inactivation prevented PanIN and PDAC formation [40]. The mice had a normal survival with pancreata of normal morphology but signs of cellular stress as expected in the presence of mutated KRAS. This finding suggests that PDK1 activity, a pivotal component of the PI3K pathway, is a critical driver of pancreatic dysplasia. This is contrary to a previous report in non-small cell lung cancer, where the RAF proto-oncogene serine/threonine protein kinase was reported to be essential for $K R A S$ driven adenocarcinoma of the lung rather than PDK1, the absence of which did not reduce tumor formation [41, 42]. Yet when CRAF was ablated in $K R A S^{G 12}$ mutated mice, it appeared to have no inhibition on PDAC formation. This suggests that although mutated $K R A S$ is a critical oncogene in several malignancies, its effectors vary depending on tissue type, demanding careful evaluation of each downstream pathway in differing cancers [40].

Although whole genome and exome sequencing have confirmed that PTEN mutations are uncommon in PDAC samples, PTEN inactivation appears to have a significant role. In 54 human PDAC samples, 70\% displayed no or low PTEN expression and $68.5 \%$ of tumors exhibited at least moderate phosphorylated panAKT-Ser ${ }^{473}$ expression compared to surrounding stroma [43]. There was also a significant negative correlation between PTEN expression and pan-AKT phosphorylation suggesting that activation of the PI3K pathway via PTEN

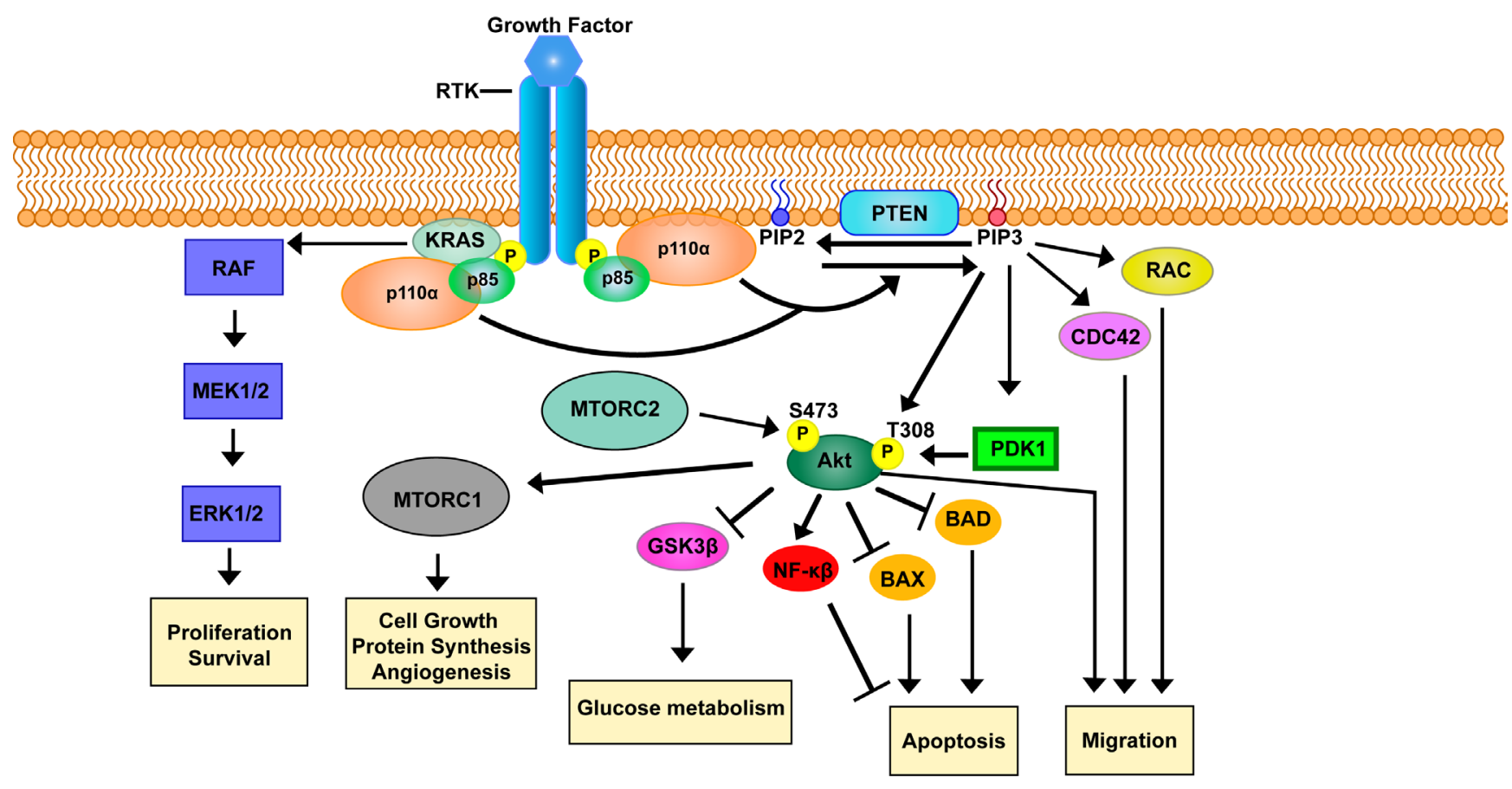

Figure 2: The class I PI3K signaling pathway through receptor tyrosine kinases. Upon binding of growth factors to receptor tyrosine kinases (RTKs), the receptor gets activated through the phosphorylation of YXXM motifs. The activation of the RTKs will result into the recruitment of $\mathrm{p} 85$ and the p110 subunits, which together forms the phosphatidylinositol 3-kinase (PI3K), to the plasma membrane in order to phosphorylate the phosphatidylinositide 4,5- bisphosphate (PIP2) and transforms it into the phosphatidylinositide 3,4,5triphosphate (PIP3). Alternatively, the PI3Ks can also be activated by KRAS, which alone can activate downstream signaling pathways such as the RAF-MEK-ERK pathway and result into cell proliferation and survival. The PI3K signaling pathway is normally inactivated through Phosphatase and tensin homolog (PTEN) converting PIP3 back into PIP2. PIP3 acts as a second messenger that can recruit AKT to the plasma membrane and activate downstream effectors such as Rac1, CDC42 and phosphoinositide-dependent kinase PDK1. Activated PDK1 is able to phosphorylate recruited AKT on the Thr308 residue. In addition, MTOR complex 2 (MTORC2) is able to phosphorylate AKT on the Ser473 residue. Phosphorylation of either or both residues of AKT results in downstream signaling events such as cell growth, protein synthesis and angiogenesis through MTORC1. Furthermore, activated AKT can also promote cell survival through inhibiting cellular processes such as glucose metabolism and apoptosis through blocking glycogen synthase kinase $3 \beta$ (GSK3 3 ) and pro-apoptotic members of the bcl-2 family; BAD and BAX respectively. Moreover, AKT can also inhibit apoptosis through the activation of Nuclear factor $\kappa \beta(\mathrm{NF}-\kappa \beta)$, and promote migration. 
loss or AKT activation is an important driver in PDAC. Furthermore, high-resolution array Comparative genomic hybridization $(\mathrm{CGH})$ analysis of 61 primary xenografts or epithelial enriched primary tumor cells revealed a deletion of either one or two copies of the PTEN locus in 9/61 samples and gain/amplification of the AKT2 isoform in 12/61 samples. One samples harbored both genetic events. Transgenic mice with heterozygoys loss of PTEN developed highly invasive pancreatic cancers compared with $P T E N$ wild type mice. All 11 mice with total loss of PTEN, developed rapidly progressive acinarductal metaplasia [ADM] and PanIN formation but there were only occasional invasive cancers. However, the lack of invasion is complicated by the early death of these mice which did not survive beyond 3 weeks; probably due to pancreatic insufficiency. Further analysis of the littermates of KRAS mutated and PTEN heterozygous mice at 4,6,8 and 10 weeks revealed that the pancreas of PTEN heterozugous mice exhibited an increased frequency and size of ADM and PanIN lesions, a more profound stromal reaction and moderately elevated phosphorylated AKT. These findings suggest that in KRAS mutated PDAC; PTEN can repress PI3K signaling and restrain cancer progression. A further study looking at the role of the PI3K/ AKT pathway in PDAC formation, examined mice with a latent oncogenic PIK3CA mutation (encoding $\mathrm{p} 110 \alpha^{\mathrm{H} 1047 \mathrm{R}}$ ) allele silenced by a lox-stop-lox (LSL) cassette as a knockin [40]. Transgenic expression of this mutation resulted in increased $\mathrm{PIP}_{3}$ levels in murine pancreata, similar to the expression seen in KRAS mutated mice. Histological review of the $P I K 3 C A$ mutated mice revealed a greater presence of ADM and all mice subsequently developed PanIN at a rate similar to $K R A S^{G 12 D}$ mice. Analysis of tissue samples revealed similar expression of several downstream components of the PI3K pathway including phosphorylated AKT-Ser ${ }^{473}$ and AKT-Thr ${ }^{308}$, pan-AKT and phosphorylated GSK $3 \beta-S$ in both models. Aged mice with either a $P I K 3 C A$ or $K R A S$ mutation developed PDAC within 800 days with comparable survival times and patterns of metastatic spread. Importantly in the tissue taken from the PIK3CA mutated mice, there was no evidence of RAS activation, excluding the possibility of upstream RAS being responsible for driving progression. PDK1 was then inactivated in murine pancreata using floxed PDK1 mice to test the importance of PDK1 in PDAC formation. Total PDK1 inactivation appeared to block PanIN and PDAC development in the KRAS ${ }^{G 12 D}$ mouse models, resulting in normal life expectancy and PI3K/AKT inactivation. Deletion of one PDK1 allele did not alter the prevalence of PanIN and PDAC. Loss

\section{Group I \\ PAK1

\begin{tabular}{|l|l|l|l|l|l|}
\hline & PBD:AID & & & & kinase \\
\hline
\end{tabular} \\ PAK2

\begin{tabular}{|l|l|l|l|l|l|}
\hline & PBD:AID & & & & kinase \\
\hline
\end{tabular} \\ $524 a a$ \\ PAK3

\begin{tabular}{|l|l|l|l|l|l|}
\hline & PBD:AID & & & & \\
\hline
\end{tabular}

\section{Group II}

PAK4

$$
\text { GBD:AID }
$$

kinase

591aa

PAK5

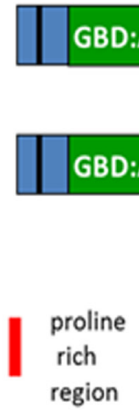

PAK6

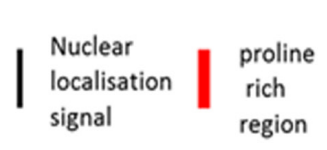

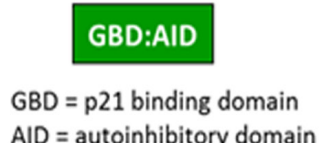

$A I D=$ autoinhibitory domain

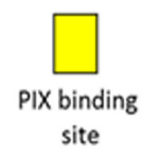

kinase

681aa

Figure 3: Domain structure of PAK family proteins. There are 6 PAK family kinases which are divided into 2 groups. Group I and II PAKS share a common domain consisting of an N-terminal p21-GTPase binding domain (GBD) and a Cterminal serine/threonine kinase domain. Group I PAKS have an Auto inhibitory Domain (AID) overlapping the GBD (GTPase Binding Domain), while the Group II PAKS contain a putative AID sequence. Group I PAKS also contain a PIX binding site in the central region. PAK4 contains a Rho-GEF interacting domain. 
of PDK1 also reduced the phosphorylation of AKT at the threonine site and its downstream effector GSK3 $\beta$-S9.

Given this wealth of evidence supporting a role for the PI3K pathway in disease progression it is perhaps not surprising that PI3K inhibitors have been tested in some of the PDAC model systems. A selective oral pan-class I PI3K inhibitor, GDC0941 has been used to treat mice harboring a $K R A S^{G 12 D}$ mutation [40]. After 14 days of treatment, GDC0941 reduced both PDAC tumor growth and phosphorylation of AKT-Thr ${ }^{308}$. This led to disease stability in contrast with vehicle-treated mice where rapid disease progression was observed. Post-mortem tissue analysis also revealed decreased proliferation markers in the GDC0941 treated tumors. In addition to the KRAS mutated mice, primary patient-derived PDAC cells were transplanted orthoptically in to the pancreas of immunodeficient mice. These mice were subsequently treated with GDC0941 and similar tumor suppressive events were recorded. These studies confirm that the PI3K-PDK1-AKT pathway is an important driver for PDAC.
A key hallmark of PDAC is the dense stroma surrounding the tumor. Cancer cells are encased in a mesh composed of stromal fibroblasts, endothelial cells and immune cells; the roles of which have yet to be fully established [44]. Significant debate surrounds the effect of the stroma on cancer progression. Previously thought to be protective of the tumor and a barrier to adequate drug delivery, recent studies have shown that depleted stroma in transgenic mice led to poorer survival with more aggressive cancers suggesting the stroma may in fact hinder tumor progression [45]. A recent study investigating heterocellular signaling (between the cancer cells and stromal cells) has revealed that $K R A S^{G 12 D}$ PDAC cells secrete growth factors including MFCSF, GCSF cytokines and the growth morphogen sonic hedgehog (SHH) which act on the stromal cell compartment, particularly pancreatic stellate cells (PSC) [46]. Interestingly this study reported that $K R A S^{G 12 D}$ expression induces canonical ERK1/2 activation, but found no evidence that AKT was activated in a cell-autonomous way. However, whilst

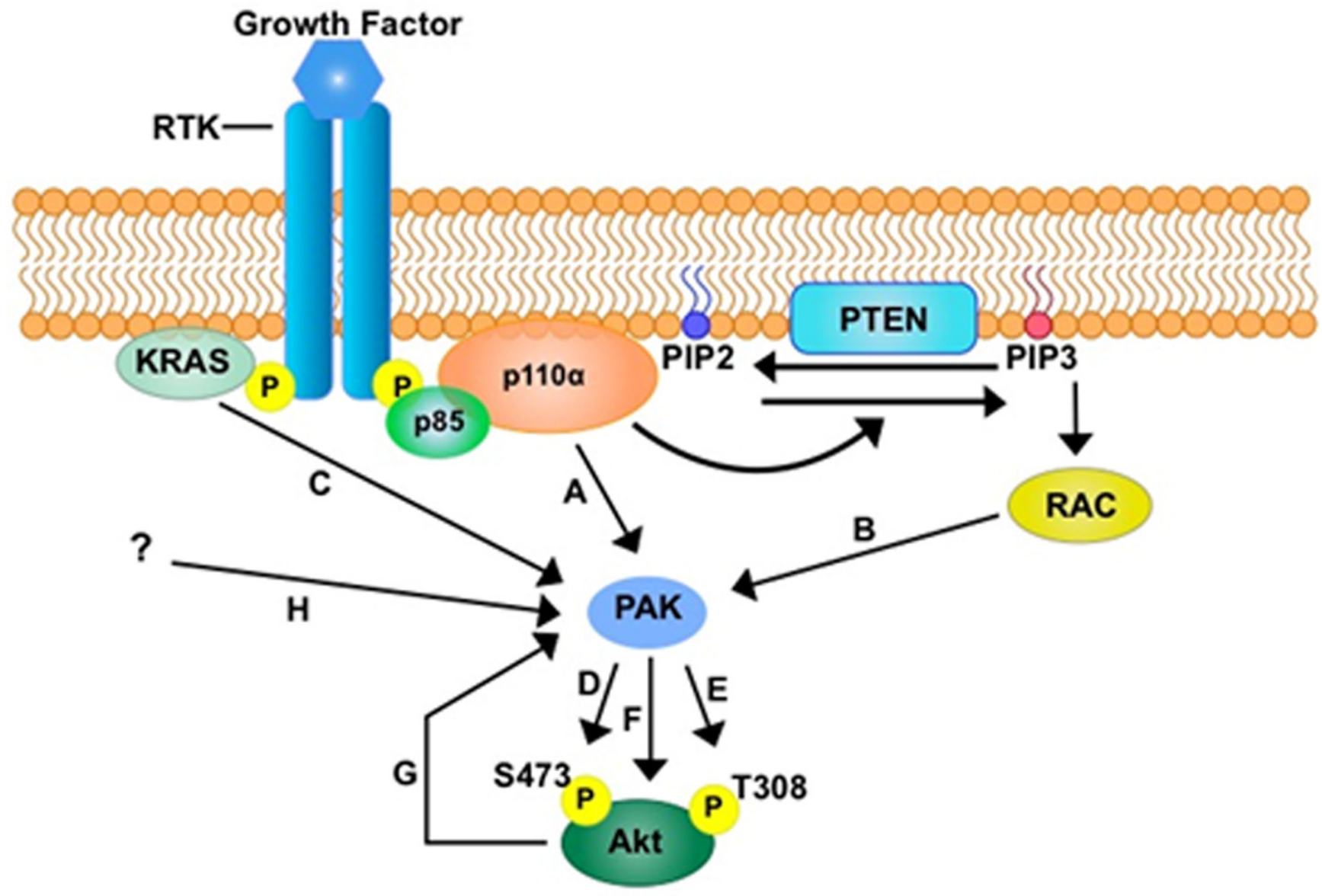

Figure 4: The potential role of PAK in PI3K signalling. PAK could be a key mediator in the PI3K-AKT signalling axis through direct activation by PI3K A. and through the activation via PIP3-RAC1 B. Furthermore, direct activation of PAK through KRAS has been suggested C. Activation of PAK has been shown to activate AKT in kinase dependent manners through the phosphorylation of either S473 D. or T308 E. or both residues, and through a kinase independent manner F. The possibility of a negative or positive feedback loop by AKT on PAK G. has not been investigated thus far. Other factors that could activate PAK are yet to be identified $\mathbf{H}$. 
AKT activation did not appear to be via expression of $K R A S^{G 12 D}$, tumor cell AKT substrates, such as GSK3 $\beta$, were elevated in the PDAC cells suggesting that $K R A S^{G 12 D}$ activates AKT reciprocally via stimulation of PSC rather than cell-autonomously. This emphasizes the need for future genomic and proteomic studies encompassing heterocellular rather than homocellular signaling in PDAC; where the stroma is present proposing AKT as a potential focal point where reciprocal signaling could occur.

\section{P-21 ACTIVATED KINASES}

Targeting either RAS or PI3K pathways has potential limitations, as there is clear evidence of complex crosstalk between the two [47]. Promising treatment strategies using MEK inhibitors for example, unwittingly activated the PI3K pathway by a negative feedback loop [48]. Whilst novel drugs targeting PI3K and its downstream targets remain in development, several have failed to show benefit in clinical trials. Unless clear oncogenic addiction to therapeutic targets has been demonstrated, the lack of patient stratification using clear predictive biomarkers in these trials may explain these recent failures. It is therefore prudent to consider alternative strategies such as targeting components that can directly and indirectly interact with the PI3K pathway including the PAKs.

There is emerging evidence to suggest that aberrant activation of PAKs can lead to tumorigenesis [16, 49]. Indeed, PAK overexpression has been identified in various solid tumors including breast, colon, prostate and importantly in PDAC [49]. There also appears to be links between PAK activity and the PI3K pathway. The PAK family comprises six non-receptor serine/threonine kinase members, divided into group 1 (PAK1-3) and group 2 (PAK4-6) (Figure 3). Each sub-group has shared and distinguishing features including differences in regulation. Even amongst the subgroups, several distinctions occur. Transgenic knock out (KO) models of PAK5 or PAK6 results in viable healthy litter, whereas PAK4 $\mathrm{KO}$ is embryonically lethal $[50,51]$. (See reviews by King et al and Radu et al for more information [49, 52]). PAKs are effectors of Rho GTPases Cdc42 and Rac, and upon activation by upstream signaling, mediate several physiological processes[53]. These include cell survival, growth and cytoskeletal dynamics affecting cell adhesion, motility and morphology [54]

\section{PAK signaling}

Phosphorylation of PAK members by PI3K, AKT and PDK1 can modulate various downstream signal events including several cellular process that, when dysregulated could contribute to the hallmarks of cancer [55-57]. Activation of members of the PAK family has been shown to promote cell survival and anti-apoptotic signaling. It has been reported that PAKs promote anchorage independent growth on soft agar in vitro, suggesting its contributions to oncogenic transformation [58-62]. Furthermore, aberrant PAK expression via direct phosphorylation of downstream $\mathrm{BAD}$, or indirectly through Raf-1, leads to reduced binding of the death protein BAD to BCL-2 and thus prevents the release of pro-apoptotic factors [63-66]. In addition, there is evidence to suggest PAK2 and PAK4 could inhibit apoptosis independently from BAD phosphorylation through phosphorylation of caspase 7 and inhibition of caspase 8 respectively $[67,68]$. PAK 1 activates the nuclear factor kappa-light-chain-enhancer $(\mathrm{NF}-\kappa \beta)$ pathway resulting in resistance to apoptosis and promoting cell growth and angiogenesis [69]. Overexpression of PAK5 inhibits caspase- 8 activity and subsequent inhibition of camptothecin induced apoptosis [70].

In addition to survival and anti-apoptotic signaling, PAK is also associated with cell cycle progression and cell proliferation [62, 71-73]. This was demonstrated to be via AKT, ERK and Wnt mediated signaling in colon cancer $[74,75]$. PAK1 can also activate the ERK pathway via Mitogen-activated Protein Kinase Kinase (MEK) phosphorylation in a kinase independent manner, with subsequent increased Cyclin D1 expression, leading to cell cycle progression [76]. PAK4 regulates cell cycle progression through phosphorylation of SMAD2/3 of the TGF- $\beta$ pathway, and by mediating the expression of cell cycle regulators p21, Cyclin D1 and CDC25A [77, 78].

As downstream effectors of the Rho GTPases Cdc42 and Rac, PAKs also play a crucial role in cancer cell migration and invasion, which could contribute toward metastases formation. PAKs are involved in cytoskeletal remodeling through increased cellular contractility via phosphorylation of myosin light chain (MLC), and interaction with microtubules through phosphorylation of GEF-H1[79, 80]. Furthermore, PAKs can induce actin filament elongation and reduce actin disassembly by phosphorylation of LIM kinase (LIMK), and actin polymerization through phosphorylation of p41-Arc, inducing Arp2/3 complex formation [80-82]. In addition, PAKs can modulate lamellipodia and filopodia formation, rapid turnover of focal adhesions by paxillin, and membrane ruffling through filamin A to promote increased cell motility [83-86]. Moreover, cell-cell junctions were found to be inhibited by PAK1 induced Snail activation, promoting dissemination of cancer cells by inducing epithelial mesenchymal transition (EMT) $[87,88]$. PAK6, one of the least well characterized family members, is required for hepatocyte growth factor (HGF) activated carcinoma cell-cell disassociation. PAK6 can drive cell-cell disassociation via an IQGAP1/E-cadherin complex leading to the phosphorylation of $\beta$-catenin and the subsequent disruption of cell-cell adhesions and $\beta$-catenin and PAK6 both localize to cell junctions [89]. PAK6 localization to the cell-cell adhesions occurs 
via the N-terminus and is $\mathrm{Cdc} 42$ dependent [90]. In osteosarcoma and breast cancer cell lines, PAK4 inhibition led to defects in the cell polarization and suppressed $\beta$-catenin phosphorylation [91]. Further work needs to be performed to translate these concepts to PDAC cells but they highlight the potential that PAKs have in cell-cell disruption and subsequent dissemination.

It has also been reported that the promotion of invasion through extracellular matrix degradation can be mediated by PAK-induced secretion of matrix metalloproteinases MMP-1, MMP-2, MMP-3 and MMP-9 [77, 92, 93]. Conversely, PAK inhibition leads to reduced migratory and less invasive potential of cancer cells [9399].

Several reports have suggested that PAKs are also involved in other cellular processes such as vasculogenesis, angiogenesis and metabolic activity [100103]. However, it is important to note that PAKs have also demonstrated numerous non-kinase dependent functions $[66,68,76]$.

\section{PAKs and cancer}

Overexpression of PAKs 1,2,4 and 6 appear to correlate with a more aggressive phenotype of cancer suggesting its potential as a prognostic biomarker [104-109]. In a study using 153 paraffin embedded tissue samples retrospectively collected from patients with advanced ovarian cancer, there was a significant association between increased PAK4 expression and reduced overall and disease free survival, reduced chemosensitivity and an increased presence of metastases [77]. PAK1 on chromosome 11q13 and PAK4 on chromosome 19q13.2 are the most commonly overexpressed members of the PAK family in malignancy. Amplified 11q13 and subsequent PAK1 expression has been identified in ovarian cancer and in breast cancer where 11q13 amplification is associated with poor prognosis. Increased PAK1 expression is also present in $B R A F$ wild type melanoma compared with $B R A F$ mutated disease. Chromosome $19 \mathrm{q} 13.2$ is recurrently amplified in PDAC, oral squamous cell carcinoma, breast cancer and ovarian cancer [52].

Even in the absence of genetic amplification, down-regulation of micro RNA 7 (miR-7) has led to overexpression of PAK1 in vitro [108, 110-114]. Similarly, PAK2 and PAK4 expression in cancer cells in vitro were reported to be negatively mediated by miR-224 and miR145 or miR-199a/b3p respectively, suggesting a regulatory role for microRNAs on PAK expression [115-117].

\section{PAK and PDAC}

Whilst the exact role of PAKs in the development of PDAC has yet to be established, higher levels of PAK1 and PAK4 have been reported in PDAC. A study looking at 202 human PDAC tissue samples found that PAK1 was overexpressed in $82 \%$ of them [118]. Furthermore, a recent study of 72 paraffin-embedded primary pancreatic cancer samples and 20 liver metastases from PDAC patients, reported that PAK1 expression was elevated in primary pancreatic cancer tissue compared with that taken from metastases [117]. PAK1 expression appeared to correlate with improved overall survival (high PAK1 expression was associated with an increased median overall survival of 23.3 months compared with 12.0 months; $p=0.004$; hazard ratio for death $=0.4$ ). However, there was no correlation with PAK1 expression and tumor stage or clinical characteristics. There are limitations to interpreting this data as it is a retrospective analysis and further prospective work is needed to validate these findings. Interestingly, these studies do not reflect in vitro reports where high levels of PAK1 expression are consistently associated with a more aggressive phenotype. Indeed, over expression of PAK1 in the PDAC cell line $\mathrm{MiaPaCa} 2$ resulted in increased proliferation, larger number of colony formation and increased migration [119]. Whilst in KRAS wild-type pancreatic cancer cell lines PAK1 overexpression led to increased colony formation. Furthermore, PAK1 depletion led to reduced migration and invasion suggesting PAK1 may play a more prominent role in KRAS-independent PDAC. In addition, a further study also confirmed that PAK1 depletion led to reduced proliferation in the PDAC cell lines MiaPaCa2 and Panc1 [120]. Thus, whilst it is clear that PAK1 over expression is present in PDAC tissue compared with normal tissue, its precise in vivo role in carcinogenesis and metastatic spread needs to be investigated further.

PAK4, a member of the group 2 PAKs, is also overexpressed in PDAC. CGH analysis on cDNA microarray of 13 PDAC cell lines identified 24 independent amplicons. Copy number increases were frequently seen at three regions of chromosome 19 (19p13.3, 19q13.1 and 19q13.3). Analysis of these loci revealed that PAK4 at 19q13.1 was frequently expressed at higher levels, correlating with increased copy number changes [113]. A subsequent study using representational oligonucleotide microarray studies analyzed 92 PDAC samples [121]. 22 PDAC cell lines, 26 surgically resected early stage PDAC samples and a further 24 xenografts of surgically resected PDAC samples were used to assess copy number variations. To increase sample size, data from the analysis of 16 primary PDAC tissue samples and 4 cell lines that had previously been published were added to the new samples resulting in a total of 92 individual PDAC samples. Several previously established genetic amplifications and deletions were identified including Tp16/CDKN2A (Ink/Arf), TP53, c-MYC, KRAS2, MADH4, TERT, EGFR, ERBB2 and znf217 as well as focal amplification at $19 \mathrm{q} 13$ in 5 patient samples and 2 cell lines. Candidate oncogenes from this region were then mapped and using immunohistochemical labeling, 
PAK4 was identified as being at the 'epicenter' of this region. In all samples harboring genomic amplification at $19 \mathrm{q} 13$, PAK4 protein expression was higher than normal. To determine the relationship between PAK4 and mutated $K R A S$, the KRAS2 gene was sequenced in the tumor samples with PAK4 amplification. Codon 12 was mutated in 4 of the 5 samples and 3 of these samples also had genomic amplification and overexpression of KRAS2. These results led the authors to suggest that the PAK4 and RAS pathways may be positively associated. However, one sample had no mutation in $K R A S 2$ or $P A K 4$, thus PAK4 amplification may also occur in the absence of KRAS activation.

qRT-PCR has also revealed increased PAK4 expression in multiple PDAC cell lines with or without the amplification suggesting PAK4 expression is not always dependent on genetic overexpression [122]. Further investigation revealed that reduced PAK4 expression in pancreatic cancer cells leads to a significant reduction in anchorage independent growth. Moreover, expression of a constitutively activated PAK4 protein promoted increased migratory capacity which could be attenuated by reduced PAK4 expression [123]. Although current studies demonstrate an oncogenic role of PAKs in PDAC, more research is needed to identify their exact mechanism and contribution towards PDAC progression. Nevertheless, these findings suggest the PAKs have a central role in the maintenance of PDAC, highlighting their potential as therapeutic targets.

\section{PAK and the PI3K pathway}

There is evidence that the PAK family can interact with various components of the PI3K pathway (Figure 4). Indeed, qPCR analysis in oral squamous cell carcinomas (OSCC), revealed co-existing PIK3CA and PAK1 amplification in $37 \%$ of recurrent tumor samples[124] . $\mathrm{PI} 3 \mathrm{~K}$ is known to stimulate the small G protein Rac, which in turn is a direct activator of both PAK1 and AKT[56]. In colorectal cancer (CRC) cells, reduced PAK 1 expression led to reduced AKT phosphorylation which correlated with a subsequent decrease in cell proliferation, migration, invasion and survival[75]. A link between PAK and AKT has also been reported in monkey fibroblast like (COS-1) cells where expression of a dominant negative mutant of PAK1, inhibited AKT1 phosphorylation [125]. In addition, the PAK1 kinase domain serves as a scaffold allowing AKT stimulation by PDK1, and aids recruitment of AKT to the cell membrane. Subsequent silencing of PAK1/ PAK2 expression also reduced activation of endogenous AKT confirming that PAK1 and PAK2 are required for phosphorylation of AKT. Surprisingly over expression of PAK1 kinase negative mutants also effectively led to the phosphorylation of AKT, suggesting that PAK1 can drive activation of AKT in a kinase independent manner. These studies also demonstrated that AKT1 could be co-immunoprecipitated with PAK1. Indeed, AKT coimmunoprecipitation with PAK1 is also reported in platelet cells further confirming the close interaction between PAK and AKT [126]. In breast cancer cells, endogenous levels of Rac1, PI3K and PAK1 were all stimulated following treatment with epidermal growth factor (EGF) leading to increased migration[127], however in cells expressing a PAK1 kinase dead mutant this migratory response to EGF was significantly diminished. Interestingly, the non-specific PI3K pathway inhibitor LY294002 reduced phosphorylation of PAK1 in these cells placing PAK1 downstream of PI3K suggesting there may in fact be a feedback loop by which the two interact. Recently increased PAK1 expression was associated with activated AKT with a trend towards significance $(p=0.05)$ in human squamous cell skin cancer (SCC) samples [128]. Transgenic mice harboring KRAS ${ }^{G 12 D}$ mutations were bred with PAK1 knock out mice to produce mice that were wild type, heterozygous or knockout for PAK1. The control mice, K5-rTA::tet-KRAS G12D, developed irregular lesions on the skin as early as five days which invariably transformed to SCC malignancies. The Pak $1^{+/-}$mice took 10 days to develop skin lesions compared to control mice and the $\mathrm{Pak}^{-/-}$mice took 25 days. The $\mathrm{PAK}^{-/}$mice also had significantly longer survival. In the $K R A S^{G 12 D}$ mice, the presence of $\mathrm{PAK}^{-/}$led to a decrease in phosphorylated AKT and downstream targets, mTOR, p70, S6K and S6. Interestingly, two PAK inhibitors, (PF03758309 that suppresses groups 1 and 2 PAK and FRAX-597 that suppresses group $1 \mathrm{PAK}$ ) led to marked tumor regression in the K5-rTA::tet-KRAS $S^{G 12 D}$ mice. Western-blot analysis of tumor samples revealed a reduction in threonine phosphorylated AKT. However, treatment with the AKT inhibitor GSK690693 did not deliver tumor regression thus the importance of AKT signaling in this context remains to be elucidated. There is also evidence that PAK can be mediated by PI3K independent from RAS activity. In breast cancer cells with both Her 2 amplification and PIK3CA mutations, treatment with a pan-PI3K inhibitor GDC0941 led to reduced AKT and Rac1/ERK activity [47]. RAS activity was paradoxically not suppressed but induced, suggesting that loss of ERK signaling can occur via a RAS independent pathway. Whilst loss of KRAS via SiRNA knockdown failed to suppress ERK phosphorylation in T47D cells (supporting the theory that this event can occur independently of KRAS activity) in a pancreatic cancer cell line, KRAS knockdown suppressed phospho-ERK activity suggesting that there may be heterogeneity in these pathways depending on tumor type.

In contrast there have been specific studies of PAK4 pathways in PDAC with evidence that PAK4 can modulate the activity of AKT. In pancreatic cancer cell lines stable PAK4 depletion led to a significant decrease in phosphorylated AKT levels [124]. Moreover, PAK4 depleted cells exhibited reduced proliferation and increased levels of cell death with a concomitant 
decrease in the accumulation of $\mathrm{NF}-\mathrm{k} \beta$ within the nucleus. In MDA-MB-231 breast cancer cells, elevated levels of PAK4 expression correlated with an elevated level of phosphorylated AKT and a more invasive phenotype [129]. Consequently, PAK4 depletion by SiRNA knockdown resulted in reduced phosphorylated AKT and reduced activity of mammalian target of rapamycin (mTOR), a downstream effector of AKT. In contrast a kinase active PAK4 (S474E) enhanced PI3K/ AKT signaling. Interestingly a kinase inactive mutant of PAK4 (K350A/K351A) continued to up drive increased levels of phosphorylated AKT suggesting the activity of PAK4 may be both kinase dependent and independent. A study of cisplatin resistant (CDDP) gastric cancer cells also confirmed that in PAK4 SiRNA depleted cells there is a reduction in phosphorylated AKT, whilst total AKT levels were unchanged [130]. PAK4 silenced CDDP gastric cancer cells were then subcutaneously injected into nude mice. Analysis of subsequent tumors with immunohistochemical staining revealed there was reduced expression of phosphorylated AKT in PAK4 depleted compared with wild type tumors. Conversely, treatment with the PI3K inhibitor LY294002 in the wild type CDDP gastric cancer cells, led to a reduction of phosphorylated PAK4 compared with control cells without affecting total PAK4 expression. This was not reproduced with a MEK/ ERK inhibitor. These results suggest that PAK4 and the $\mathrm{PI} 3 \mathrm{~K} / \mathrm{AKT}$ pathway can reciprocally activate each other.

\section{TARGETING THE PI3K AND PAK PATHWAY IN PDAC}

Despite a paradigm shift toward molecularly targeted therapies in many solid malignancies, management of advanced PDAC has largely been left unaffected by these changes and response to cytotoxic chemotherapy is poor. Two chemotherapy regimens have improved survival of advanced PDAC in recent years. FOLFIRINOX, a triplet combination which offers a median overall survival (OS) of 11.1 months compared with 6.8 months for gemcitabine alone in a phase III trial $(p<0.001)$ [3]. An alternative treatment regimen is Nab-Paclitaxel and gemcitabine which improved median OS to 8.5 months compared with 6.7 months for gemcitabine $(p<0.001)$ [2]. The only phase III trial of a targeted therapy to meet its primary endpoint of improved survival was the anti-epidermal growth factor (EGFR) small molecule inhibitor erlotinib, which when combined with gemcitabine offered a marginal survival benefit of a couple of weeks [131]. Unlike lung cancer, the presence of an EGFR mutation was not predictive of response. Yet analysis of patients who experienced cutaneous toxicity revealed that the presence of a skin rash was associated with a higher likelihood of achieving disease control $(P$ $=.05$ ) after other prognostic factors were controlled for. These results seemed to suggest that there may be a cohort of patients who responded to therapy, highlighting the need for predictive biomarkers. The failure of molecularly targeted therapies so far suggests that patients need to be stratified by genomic expression and treated according to suspected oncogenic drivers. Therefore, the search for more effective therapy has fueled the evaluation of several novel targets for PDAC.

The RAS/PI3K/PDK1/AKT pathway is an exciting target. Targeting RAS has proven challenging with previous attempts to inhibit $K R A S$ unsuccessful due to the inability to find an allosteric binding point on mutated RAS. This is likely due to its high binding affinity with GTP. Post-translational modification of RAS proteins (required for membrane anchorage) using farnesyltransferase inhibitors failed to improve survival in clinical trials when used in conjunction with chemotherapy [132]. Further attempts using an orthosteric inhibitor of the RASSOS interaction are promising but have yet to make it to clinical trials [133]. Small molecules that can irreversibly bind to a common mutant $K R A S^{(\mathrm{G} 12 \mathrm{C})}$ are in development. The discovery of a new allosteric regulatory site meant these novel inhibitors bind to a newly discovered regulatory site leading to disruption of both switch-1 and switch-2 leading to reduced GTP binding and subsequent activity [134]. Further studies are warranted to determine clinical activity of these agents. Targeting a protein upstream in prominent oncogenic pathways can be a double-edged sword with normal cellular function at risk of unwarranted inhibition, resulting in potential toxicities. Therefore, research has focused on down-stream targets. Careful selection of the right constituent of the pathway is paramount to maximize efficacy without compromising safety.

\section{Targeting PI3K pathway}

Blockage of the PI3K pathway has yielded some promising results. Several agents that target various components of the PI3K pathway are in development (Table 1). These include pan-Class1 and isoform-specific PI3K inhibitors, dual PI3K -mTOR inhibitors, pan and isoform-specific AKT inhibitors and allosteric mTOR, AKT and PDK1 inhibitors [135]. The PDK1 inhibitor BX912, the dual class 1 PI3K-mTOR inhibitor NPVBEZ235 and the AKT inhibitor MK-2206 all show evidence of blocking acinar-ductal metaplasia [136] formation in primary PDAC xenografts. NVP-BEZ235, demonstrated inhibited tumor growth in orthoptic pancreatic xenografts [137]. The potent and selective oral pan-class 1 PI3K inhibitor GDC0941 effectively inhibited the growth of primary $K R A S^{G 12 D}$ murine and primary human patient derived PDAC cells in vivo. In KRAS mutated mice, GDC0941 efficiently blocked tumor growth with decreased cell proliferation after 14 days of treatment [40]. Treated cells showed a reduction in the phosphorylation of AKT-Thr ${ }^{308}$ highlighting AKT activity 
Table 1: Table of drug inhibitors targeting the PI3K-PAK-Akt pathway in cancers.

\begin{tabular}{|c|c|c|c|c|}
\hline Drug & Developed by & Target & Clinical Trials & Ref \\
\hline $\begin{array}{l}\text { GDC0941 } \\
\text { Pictilisib }\end{array}$ & $\begin{array}{l}\text { Genentech } \\
\text { /Roche }\end{array}$ & $\begin{array}{l}\text { Pan class } 1 \text { PI3K } \\
\text { inhibitor }\end{array}$ & $\begin{array}{l}\text { Completed Phase I/II trials for breast cancer, non- } \\
\text { small cell lung cancer, non-Hodgkin's lymphoma and } \\
\text { advanced solid cancers. }\end{array}$ & {$[138]$} \\
\hline BX912 & Berlex Bioscience & PDK1 inhibitor & $\mathrm{N} / \mathrm{A}$ & {$[148]$} \\
\hline NVP-BEZ235 & Novartis & $\begin{array}{l}\text { PI3K-mTOR } \\
\text { inhibitor }\end{array}$ & $\begin{array}{l}\text { Completed Phase I/II trials for breast cancer, } \\
\text { leukemia, castrate resistant prostate cancer, pancreatic } \\
\text { neuroendocrine tumors and advanced solid tumors }\end{array}$ & {$[149]$} \\
\hline MK2206 & Merck & $\begin{array}{l}\text { Allosteric } \\
\text { Pan-AKT } \\
\text { inhibitor }\end{array}$ & $\begin{array}{l}\text { Active Phase I/II trials for breast cancer, colon cancer, } \\
\text { endometrial carcinoma, pancreatic adenocarcinoma, } \\
\text { prostate cancer and renal cell carcinoma. Completed } \\
\text { Phase I/II trials for breast cancer, acute and chronic } \\
\text { myeloid leukemia, lung carcinoma, ovarian sarcoma, } \\
\text { pancreatic acinar carcinoma, pancreatic neuroendocrine } \\
\text { tumors and advanced solid tumors. }\end{array}$ & {$[150]$} \\
\hline $\begin{array}{l}\text { AZD6244 } \\
\text { Selumetinib }\end{array}$ & \begin{tabular}{|l|} 
Array BioPharma \\
(Licensed by \\
Astrazeneca)
\end{tabular} & $\begin{array}{l}\text { MEK } 1 / 2 \\
\text { inhibitor }\end{array}$ & $\begin{array}{l}\text { Completed/Active Phase I/II trials for breast cancer, } \\
\text { lung cancer, melanoma, pancreatic adenocarcinoma and } \\
\text { solid tumors }\end{array}$ & {$[151]$} \\
\hline $\begin{array}{l}\text { GSK- } \\
1120212\end{array}$ & GlaxoSmithKline & $\begin{array}{l}\text { MEK } 1 / 2 \\
\text { Inhibitor }\end{array}$ & $\begin{array}{l}\text { Completed/Active Phase I/II/III trials for lung cancer, } \\
\text { melanoma, recurrent leukemia and solid tumors }\end{array}$ & {$[152]$} \\
\hline $\begin{array}{l}\text { GSK } \\
690693\end{array}$ & GlaxoSmithKline & $\begin{array}{l}\text { AKT } \\
\text { inhibitor }\end{array}$ & N/A & {$[153]$} \\
\hline FRAX597 & $\begin{array}{l}\text { Scripps Research } \\
\text { Institute }\end{array}$ & $\begin{array}{l}\text { PAK1 } \\
\text { inhibitor }\end{array}$ & N/A & {$[154]$} \\
\hline PF-3758309 & Pfizer & $\begin{array}{l}\text { PAK4 } \\
\text { inhibitor }\end{array}$ & N/A & {$[144]$} \\
\hline KPT-7189 & Karyopharm & $\begin{array}{l}\text { PAK4 } \\
\text { inhibitor }\end{array}$ & N/A & {$[145]$} \\
\hline LY294002 & Eli Lilly & $\begin{array}{l}\text { Reversible } \\
\text { PI3K inhibitor }\end{array}$ & Active Phase I for neuroblastoma & {$[155]$} \\
\hline $\begin{array}{l}\text { NVP- } \\
\text { BKM120 }\end{array}$ & Novartis & $\begin{array}{l}\text { Pan class I PI3K } \\
\text { inhibitor }\end{array}$ & Active Phase III for metastatic breast cancer & {$[156]$} \\
\hline
\end{tabular}

as a potential surrogate marker for disease response. GDC0941 has been evaluated in an early phase study, with confirmation of pharmacodynamics response and preliminary evidence of efficacy [138]. Ongoing trials are underway with GDC0941 and other pan-Class I PI3K inhibitors, but are unlikely to yield meaningful responses as single agents due to complexity of feedback loops and crosstalk across linked signaling pathways.

Dual inhibition to counteract this cross-pathway activation is therefore likely to yield more effective results. The MEK1/2 inhibitor, AZD6244 was tested in combination with two PI3K inhibitors NVP-BKM120 or GDC0941 in transgenic mice and PDAC cell lines. Although MEK inhibition alone was cytostatic, the combination with either PI3K inhibitor led to apoptosis. In $K R A S^{G 12 D}$ mice, dual inhibition delayed PDAC formation and improved survival although responses were not durable [139]. The combined use of the MEK inhibitor GSK1120212 and the AKT inhibitor GSK690693 resulted in statistically significant synergy in PDAC cell lines with decreased phosphorylation of the downstream effector of AKT, RPS6, compared with either agent alone suggesting
AKT inhibition could potentiate the response of targeting MAPK [140].

\section{Targeting PAK}

PAK inhibitors have also demonstrated modest efficacy in cell lines although preliminary uses of group 1 PAK inhibitors were largely unsuccessful. Group 1 PAKs have a large ATP binding pocket with high conformational flexibility that likely impeded the identification of highaffinity ligands [141, 142]. However, the PAK1 inhibitor FRAX597 has shown evidence of decreasing PDAC cell proliferation, migration and survival. In addition when combined with the chemotherapeutic agent gemcitabine, FRAX597 synergistically inhibited PDAC proliferation both in vivo and in vitro [120].

PAK4 is also a promising target. PF-3758309 is a potent $(\mathrm{Kd}=2.7 \mathrm{nM})$, ATP competitive, pyrolopyrazole inhibitor of PAK4 [143]. As selective downstream targets of PAK4 are unknown, a PAK4 specific assay was constructed with an inducible expression of a PAK4 
catalytic domain in cells that are also overexpressing GEF-H1 allowing PAK4 phosphorylation of GEF-H1 to be readily detected; which was shown to be suppressed by PF-3758309 $\left(\mathrm{IC}_{50}=1.3+/-0.5 \mathrm{nM}\right)$. Subsequently, PF3758309 was found to inhibit cellular proliferation and anchorage independent growth across a panel of 92 cell lines including 28 PDAC lines. In the PDAC cell lines, the $\mathrm{IC}_{50}$ ranged from 12nM (Panc0813) to $2380 \mathrm{nM}$ (HS700T) although it is not known whether this correlates with PAK4 expression. In tumor xenografts of colon, breast, lung, melanoma and stomach, PF-3758309 impaired tumor growth with a plasma $\mathrm{EC}_{50}$ of $0.4 \mathrm{nM}$.

Pre-clinical results were encouraging and PF3758309 was subsequently tested in a phase 1 study of 33 patients with advanced cancer, including two with PDAC [144]. This was the first and only clinical trial of a PAK4 inhibitor thus far. Patients were treated with the drug orally in a standard $3+3$ design and the median number of cycles was 3 (1-10). 9 patients had grade 3 or 4 adverse events and 2 had serious adverse events (abdominal pain and hemoptysis). 1 patient died from progressive disease whilst on treatment. The pharmacokinetic data revealed that after reaching Cmax within 5 hours of dosing, PF3758309 plasma concentration reduced in a multiexponential manner with an average terminal half-life of 12.4 to 17.8 hours across doses. There was an absence of dose proportionality in the dose range of 10 to 60 $\mathrm{mg}$, which the investigators suggested was likely due to inter-patient variability. There were no tumor responses seen and the study was terminated due to unwarranted pharmacokinetic findings which were thought to be a result of excessive drug efflux, leading to off-target effects. Yet despite these disappointing preliminary results, the development of more specific PAK inhibitors are underway. It may be that improved specificity can reduce some the off target effects seen with the Pan-PAK inhibitor. In addition, understanding the link between PAK and the PI3K pathway may help identify predictive biomarkers which would help to better identify those patients who may benefit from targeted PAK therapy.

A small molecule PAK4 allosteric modulator KPT7189 has been shown to suppress PAK4 protein expression in PDAC cell lines, with associated significant reduction in cell proliferation [145]. Moreover, KPT-7189 inhibited the spheroid forming ability of PDAC cells with suppression of EMT and CSC markers. Pre-clinical efficacy studies using a similar anti-PAK4 therapeutic, KPT-7189 with KRAS mutated mice are on-going.

There is also evidence that PAK inhibitors may be used in combination with traditional chemotherapy or used in disease that is chemo-refractory. In 3 PDAC cell lines, Capan-2, PANC1 and SNU-410 that were found to be resistant to gemcitabine, the addition of the PAK4 siRNA appeared to have an effect on cell viability compared with SIRNA silencing of PAK4 or chemotherapy alone suggesting the combination of chemotherapy and PAK4 inhibition warrants further investigation[146]

Ideally, any targeted anti-cancer treatment will be used alongside known predictive biomarkers to identify patients that will benefit from treatment. A disease as complex as PDAC, is likely to require tailored management rather than a 'one hat fits all' approach. The failure of several targeted agents in clinical trials is disappointing but perhaps not surprising given the heterogeneous nature of this disease. It is possible that drugs will only work in a sub-group of patients if their complementary pathway is aberrantly activated and predetermined biomarkers are needed to ensure that potential positive responses are not diluted in large clinical trials. Furthermore even when an effective target is identified, clinical responses are often followed by progression due to the development of resistance as seen in patients with $B R A F$ mutated melanoma treated with $B R A F$ mutant inhibitors [147]. Therefore, a greater understanding of pertinent pathways and novel targets are warranted.

PAK expression in the tumor tissue and genomic amplification may provide both a prognostic and predictive biomarker for novel therapies. For example, if PAK inhibition can modulate the PI3K pathway, activity of AKT may prove to be surrogate marker of efficacy. Conversely, elevated PAK expression may help identify patients that would benefit from inhibitors of the PI3K pathway.

\section{FUTURE DIRECTIONS}

PDAC is a devastating cancer with a lack of effective therapies for patients with advanced disease. Whilst KRAS mutations occur at a frequency of nearly $100 \%$ in PDAC, the challenges of inhibiting RAS have meant efforts have been diverted to unraveling the interacting pathways both downstream from RAS, and those which are independent from RAS. The PAKs have been identified as a potential prognostic marker in several malignancies and their proposed links to the PI3K pathway warrant further attention. Despite the disappointment of several negative clinical trials, great strides have been made in improving our understanding of PDAC biology. This enhanced knowledge will hopefully translate into the development of effective targeted therapies, finally resulting in a much-needed improvement in the treatment of patients with PDAC.

\section{FUNDING SUPPORT}

The authors acknowledge financial support from the following:

Department of Health via the National Institute for Health Research (NIHR) Biomedical Research Centre award to Guy's \& St Thomas' NHS Foundation Trust in partnership with King's College London and King's College Hospital NHS Foundation Trust. King's College 
London is a UK Experimental Cancer Medicine Centre.

K.T. is the recipient of a Clinical Research Training Fellowship from The Wellcome Trust and a Cancer Research UK training bursary. H.L. is funded/ supported by the National Institute for Health Research (NIHR) Biomedical Research Centre based at Guy's and St Thomas' NHS Foundation Trust and King's College London. The views expressed are those of the author(s) and not necessarily those of the NHS, the NIHR or the Department of Health.

\section{CONFLICTS OF INTEREST}

No potential conflicts of interest.

\section{REFERENCES}

1. Rahib L, Smith BD, Aizenberg R, Rosenzweig AB, Fleshman JM and Matrisian LM. Projecting cancer incidence and deaths to 2030: the unexpected burden of thyroid, liver, and pancreas cancers in the United States. Cancer research. 2014; 74:2913-2921.

2. Von Hoff DD, Ervin T, Arena FP, Chiorean EG, Infante J, Moore M, Seay T, Tjulandin SA, Ma WW, Saleh MN, Harris M, Reni M, Dowden S, Laheru D, Bahary N, Ramanathan RK, et al. Increased survival in pancreatic cancer with nab-paclitaxel plus gemcitabine. The New England journal of medicine. 2013; 369:1691-1703.

3. Conroy T, Desseigne F, Ychou M, Bouche O, Guimbaud R, Becouarn Y, Adenis A, Raoul JL, Gourgou-Bourgade S, de la Fouchardiere C, Bennouna J, Bachet JB, KhemissaAkouz F, Pere-Verge D, Delbaldo C, Assenat E, et al. FOLFIRINOX versus gemcitabine for metastatic pancreatic cancer. The New England journal of medicine. 2011; $364: 1817-1825$

4. Jones S, Zhang X, Parsons DW, Lin JC, Leary RJ, Angenendt P, Mankoo P, Carter H, Kamiyama H, Jimeno A, Hong SM, Fu B, Lin MT, Calhoun ES, Kamiyama $\mathrm{M}$, Walter $\mathrm{K}$, et al. Core signaling pathways in human pancreatic cancers revealed by global genomic analyses. Science. 2008; 321:1801-1806.

5. Samuel N and Hudson TJ. The molecular and cellular heterogeneity of pancreatic ductal adenocarcinoma. Nature reviews Gastroenterology \& hepatology. 2012; 9:77-87.

6. Campbell PJ, Yachida S, Mudie LJ, Stephens PJ, Pleasance ED, Stebbings LA, Morsberger LA, Latimer C, McLaren S, Lin ML, McBride DJ, Varela I, Nik-Zainal SA, Leroy C, Jia M, Menzies A, et al. The patterns and dynamics of genomic instability in metastatic pancreatic cancer. Nature. 2010; 467:1109-1113.

7. Kim MS, Zhong Y, Yachida S, Rajeshkumar NV, Abel ML, Marimuthu A, Mudgal K, Hruban RH, Poling JS, Tyner JW, Maitra A, Iacobuzio-Donahue CA and Pandey A. Heterogeneity of pancreatic cancer metastases in a single patient revealed by quantitative proteomics. Molecular \& cellular proteomics. 2014; 13:2803-2811.

8. Matthaei H, Dal Molin M and Maitra A. Identification and analysis of precursors to invasive pancreatic cancer. Methods in molecular biology. 2013; 980:1-12.

9. Hruban RH, Maitra A, Kern SE and Goggins M. Precursors to pancreatic cancer. Gastroenterology clinics of North America. 2007; 36:831-849, vi.

10. Matthaei H, Schulick RD, Hruban RH and Maitra A. Cystic precursors to invasive pancreatic cancer. Nature reviews Gastroenterology \& hepatology. 2011; 8:141-150.

11. Hruban RH, Goggins $M$, Parsons $J$ and Kern SE. Progression model for pancreatic cancer. Clinical cancer research. 2000; 6:2969-2972.

12. Maitra A and Hruban RH. Pancreatic cancer. Annual review of pathology. 2008; 3:157-188.

13. Smit VT, Boot AJ, Smits AM, Fleuren GJ, Cornelisse CJ and Bos JL. KRAS codon 12 mutations occur very frequently in pancreatic adenocarcinomas. Nucleic acids research. 1988; 16:7773-7782.

14. Biankin AV, Waddell N, Kassahn KS, Gingras MC, Muthuswamy LB, Johns AL, Miller DK, Wilson PJ, Patch AM, Wu J, Chang DK, Cowley MJ, Gardiner BB, Song S, Harliwong I, Idrisoglu S, et al. Pancreatic cancer genomes reveal aberrations in axon guidance pathway genes. Nature. 2012; 491:399-405.

15. Waddell N, Pajic M, Patch AM, Chang DK, Kassahn KS, Bailey P, Johns AL, Miller D, Nones K, Quek K, Quinn MC, Robertson AJ, Fadlullah MZ, Bruxner TJ, Christ AN, Harliwong I, et al. Whole genomes redefine the mutational landscape of pancreatic cancer. Nature. 2015; 518:495-501.

16. Hingorani SR, Petricoin EF, Maitra A, Rajapakse V, King C, Jacobetz MA, Ross S, Conrads TP, Veenstra TD, Hitt BA, Kawaguchi Y, Johann D, Liotta LA, Crawford HC, Putt ME, Jacks T, et al. Preinvasive and invasive ductal pancreatic cancer and its early detection in the mouse. Cancer cell. 2003; 4:437-450.

17. Bryant KL, Mancias JD, Kimmelman AC and Der CJ. KRAS: feeding pancreatic cancer proliferation. Trends in biochemical sciences. 2014; 39:91-100.

18. Cowley MJ, Chang DK, Pajic M, Johns AL, Waddell N, Grimmond SM and Biankin AV. Understanding pancreatic cancer genomes. Journal of hepato-biliary-pancreatic sciences. 2013; 20:549-556.

19. Hruban RH, Wilentz RE and Maitra A. Identification and analysis of precursors to invasive pancreatic cancer. Methods in molecular medicine. 2005; 103:1-13.

20. Iacobuzio-Donahue CA, Velculescu VE, Wolfgang CL and Hruban RH. Genetic basis of pancreas cancer development and progression: insights from whole-exome and wholegenome sequencing. Clinical cancer research. 2012; 18:4257-4265.

21. Chang DK, Grimmond SM and Biankin AV. Pancreatic cancer genomics. Current opinion in genetics \& development. 2014; 24:74-81. 
22. Bailey P, Chang DK, Nones K, Johns AL, Patch AM, Gingras MC, Miller DK, Christ AN, Bruxner TJ, Quinn MC, Nourse C, Murtaugh LC, Harliwong I, Idrisoglu S, Manning S, Nourbakhsh E, et al. Genomic analyses identify molecular subtypes of pancreatic cancer. Nature. 2016; $531: 47-52$.

23. Chantrill LA, Nagrial AM, Watson C, Johns AL, MartynSmith M, Simpson S, Mead S, Jones MD, Samra JS, Gill AJ, Watson N, Chin VT, Humphris JL, Chou A, Brown B, Morey A, et al. Precision Medicine for Advanced Pancreas Cancer: The Individualized Molecular Pancreatic Cancer Therapy (IMPaCT) Trial. Clinical cancer research. 2015; 21:2029-2037.

24. Samatar AA and Poulikakos PI. Targeting RAS-ERK signalling in cancer: promises and challenges. Nature reviews Drug discovery. 2014; 13:928-942.

25. Hanahan D and Weinberg RA. Hallmarks of cancer: the next generation. Cell. 2011; 144:646-674.

26. Yuan TL and Cantley LC. PI3K pathway alterations in cancer: variations on a theme. Oncogene. 2008; 27:54975510 .

27. Cantley LC. The phosphoinositide 3-kinase pathway. Science. 2002; 296:1655-1657.

28. Courtney KD, Corcoran RB and Engelman JA. The PI3K pathway as drug target in human cancer. Journal of clinical oncology. 2010; 28:1075-1083.

29. Fruman DA and Rommel C. PI3K and cancer: lessons, challenges and opportunities. Nature reviews Drug discovery. 2014; 13:140-156.

30. Samuels Y, Wang Z, Bardelli A, Silliman N, Ptak J, Szabo S, Yan H, Gazdar A, Powell SM, Riggins GJ, Willson JK, Markowitz S, Kinzler KW, Vogelstein B and Velculescu VE. High frequency of mutations of the PIK3CA gene in human cancers. Science. 2004; 304:554.

31. Karakas B, Bachman KE and Park BH. Mutation of the PIK3CA oncogene in human cancers. British journal of cancer. 2006; 94:455-459.

32. Shi J, Yao D, Liu W, Wang N, Lv H, Zhang G, Ji M, $\mathrm{Xu} \mathrm{L}, \mathrm{He}$ N, Shi B and Hou P. Highly frequent PIK3CA amplification is associated with poor prognosis in gastric cancer. BMC cancer. 2012; 12:50.

33. Toker A and Newton AC. Akt/protein kinase B is regulated by autophosphorylation at the hypothetical PDK-2 site. J Biol Chem. 2000; 275:8271-8274.

34. Inoki $\mathrm{K}, \mathrm{Li} \mathrm{Y}, \mathrm{Zhu} \mathrm{T}, \mathrm{Wu} \mathrm{J}$ and Guan KL. TSC2 is phosphorylated and inhibited by Akt and suppresses mTOR signalling. Nat Cell Biol. 2002; 4:648-657.

35. Lynch DK and Daly RJ. PKB-mediated negative feedback tightly regulates mitogenic signalling via Gab2. The EMBO journal. 2002; 21:72-82.

36. Franke TF and Cantley LC. Apoptosis. A Bad kinase makes good. Nature. 1997; 390:116-117.

37. Engelman JA, Luo J and Cantley LC. The evolution of phosphatidylinositol 3-kinases as regulators of growth and metabolism. Nature reviews Genetics. 2006; 7:606-619.

38. Georgescu MM, Kirsch KH, Akagi T, Shishido T and Hanafusa H. The tumor-suppressor activity of PTEN is regulated by its carboxyl-terminal region. Proceedings of the National Academy of Sciences of the United States of America. 1999; 96:10182-10187.

39. Edling CE, Selvaggi F, Buus R, Maffucci T, Di Sebastiano P, Friess H, Innocenti P, Kocher HM and Falasca M. Key role of phosphoinositide 3-kinase class IB in pancreatic cancer. Clinical cancer research. 2010; 16:4928-4937.

40. Eser S, Reiff N, Messer M, Seidler B, Gottschalk K, Dobler M, Hieber M, Arbeiter A, Klein S, Kong B, Michalski CW, Schlitter AM, Esposito I, Kind AJ, Rad L, Schnieke AE, et al. Selective requirement of PI3K/PDK1 signaling for Kras oncogene-driven pancreatic cell plasticity and cancer. Cancer cell. 2013; 23:406-420.

41. Blasco RB, Francoz S, Santamaria D, Canamero M, Dubus $\mathrm{P}$, Charron J, Baccarini M and Barbacid M. c-Raf, but not B-Raf, is essential for development of K-Ras oncogenedriven non-small cell lung carcinoma. Cancer cell. 2011; 19:652-663.

42. Karreth FA, Frese KK, DeNicola GM, Baccarini M and Tuveson DA. C-Raf is required for the initiation of lung cancer by K-Ras(G12D). Cancer discovery. 2011; 1:128136.

43. Ying H, Elpek KG, Vinjamoori A, Zimmerman SM, Chu GC, Yan H, Fletcher-Sananikone E, Zhang H, Liu Y, Wang W, Ren X, Zheng H, Kimmelman AC, Paik JH, Lim $\mathrm{C}$, Perry SR, et al. PTEN is a major tumor suppressor in pancreatic ductal adenocarcinoma and regulates an NFkappaB-cytokine network. Cancer discovery. 2011; 1:158169.

44. Erkan M, Hausmann S, Michalski CW, Fingerle AA, Dobritz M, Kleeff $\mathrm{J}$ and Friess $\mathrm{H}$. The role of stroma in pancreatic cancer: diagnostic and therapeutic implications. Nature reviews Gastroenterology \& hepatology. 2012; 9:454-467.

45. Rhim AD, Oberstein PE, Thomas DH, Mirek ET, Palermo CF, Sastra SA, Dekleva EN, Saunders T, Becerra CP, Tattersall IW, Westphalen CB, Kitajewski J, FernandezBarrena MG, Fernandez-Zapico ME, Iacobuzio-Donahue C, Olive KP, et al. Stromal elements act to restrain, rather than support, pancreatic ductal adenocarcinoma. Cancer cell. 2014; 25:735-747.

46. Tape CJ, Ling S, Dimitriadi M, McMahon KM, Worboys JD, Leong HS, Norrie IC, Miller CJ, Poulogiannis G, Lauffenburger DA and Jorgensen C. Oncogenic KRAS Regulates Tumor Cell Signaling via Stromal Reciprocation. Cell. 2016; 165:1818.

47. Ebi H, Costa C, Faber AC, Nishtala M, Kotani H, Juric D, Della Pelle P, Song Y, Yano S, Mino-Kenudson M, Benes $\mathrm{CH}$ and Engelman JA. PI3K regulates MEK/ERK signaling in breast cancer via the Rac-GEF, P-Rex1. Proceedings of the National Academy of Sciences of the United States of America. 2013; 110:21124-21129. 
48. Mirzoeva OK, Collisson EA, Schaefer PM, Hann B, Hom YK, Ko AH and Korn WM. Subtype-specific MEKPI3 kinase feedback as a therapeutic target in pancreatic adenocarcinoma. Molecular cancer therapeutics. 2013; 12:2213-2225.

49. King H, Nicholas NS and Wells CM. Role of p-21-activated kinases in cancer progression. International review of cell and molecular biology. 2014; 309:347-387.

50. Li X and Minden A. Targeted disruption of the gene for the PAK5 kinase in mice. Mol Cell Biol. 2003; 23:7134-7142.

51. Qu J, Li X, Novitch BG, Zheng Y, Kohn M, Xie JM, Kozinn S, Bronson R, Beg AA and Minden A. PAK4 kinase is essential for embryonic viability and for proper neuronal development. Mol Cell Biol. 2003; 23:7122-7133.

52. Radu M, Semenova G, Kosoff R and Chernoff J. PAK signalling during the development and progression of cancer. Nature reviews Cancer. 2014; 14:13-25.

53. Arias-Romero LE and Chernoff J. A tale of two Paks. Biol Cell. 2008; 100:97-108.

54. Rane CK and Minden A. P21 activated kinases: structure, regulation, and functions. Small GTPases. 2014; 5.

55. King CC, Gardiner EM, Zenke FT, Bohl BP, Newton AC, Hemmings BA and Bokoch GM. p21-activated kinase (PAK1) is phosphorylated and activated by 3-phosphoinositide-dependent kinase-1 (PDK1). J Biol Chem. 2000; 275:41201-41209.

56. Tang Y, Zhou H, Chen A, Pittman RN and Field J. The Akt proto-oncogene links Ras to Pak and cell survival signals. J Biol Chem. 2000; 275:9106-9109.

57. Tsakiridis $\mathrm{T}$, Taha $\mathrm{C}$, Grinstein $\mathrm{S}$ and Klip A. Insulin activates a p21-activated kinase in muscle cells via phosphatidylinositol 3-kinase. J Biol Chem. 1996; 271:19664-19667.

58. Vadlamudi RK, Adam L, Wang RA, Mandal M, Nguyen D, Sahin A, Chernoff J, Hung MC and Kumar R. Regulatable expression of p21-activated kinase-1 promotes anchorageindependent growth and abnormal organization of mitotic spindles in human epithelial breast cancer cells. J Biol Chem. 2000; 275:36238-36244.

59. Marlin JW, Eaton A, Montano GT, Chang YW and Jakobi R. Elevated p21-activated kinase 2 activity results in anchorage-independent growth and resistance to anticancer drug-induced cell death. Neoplasia. 2009; 11:286-297.

60. Qu J, Cammarano MS, Shi Q, Ha KC, de Lanerolle P and Minden A. Activated PAK4 regulates cell adhesion and anchorage-independent growth. Mol Cell Biol. 2001; 21:3523-3533.

61. Callow MG, Clairvoyant F, Zhu S, Schryver B, Whyte DB, Bischoff JR, Jallal B and Smeal T. Requirement for PAK4 in the anchorage-independent growth of human cancer cell lines. J Biol Chem. 2002; 277:550-558.

62. Fang ZP, Jiang BG, Gu XF, Zhao B, Ge RL and Zhang FB. P21-activated kinase 5 plays essential roles in the proliferation and tumorigenicity of human hepatocellular carcinoma. Acta pharmacologica Sinica. 2014; 35:82-88.

63. Ye DZ, Jin S, Zhuo Y and Field J. p21-Activated kinase 1 (Pak1) phosphorylates BAD directly at serine 111 in vitro and indirectly through Raf-1 at serine 112. PloS one. 2011; 6:e27637.

64. Jin S, Zhuo Y, Guo W and Field J. p21-activated Kinase 1 (Pak1)-dependent phosphorylation of Raf-1 regulates its mitochondrial localization, phosphorylation of BAD, and Bcl-2 association. J Biol Chem. 2005; 280:24698-24705.

65. Cotteret S, Jaffer ZM, Beeser A and Chernoff J. p21Activated kinase 5 (Pak5) localizes to mitochondria and inhibits apoptosis by phosphorylating BAD. Mol Cell Biol. 2003; 23:5526-5539.

66. Gnesutta N, Qu J and Minden A. The serine/threonine kinase PAK4 prevents caspase activation and protects cells from apoptosis. J Biol Chem. 2001; 276:14414-14419.

67. Li X, Wen W, Liu K, Zhu F, Malakhova M, Peng C, Li T, Kim HG, Ma W, Cho YY, Bode AM, Dong Z and Dong Z. Phosphorylation of caspase-7 by $\mathrm{p} 21$-activated protein kinase (PAK) 2 inhibits chemotherapeutic drug-induced apoptosis of breast cancer cell lines. J Biol Chem. 2011; 286:22291-22299.

68. Gnesutta N and Minden A. Death receptor-induced activation of initiator caspase 8 is antagonized by serine/ threonine kinase PAK4. Mol Cell Biol. 2003; 23:78387848 .

69. Friedland JC, Lakins JN, Kazanietz MG, Chernoff J, Boettiger D and Weaver VM. alpha6beta4 integrin activates Rac-dependent p21-activated kinase 1 to drive NF-kappaBdependent resistance to apoptosis in 3D mammary acini. Journal of cell science. 2007; 120:3700-3712.

70. Wang X, Gong W, Qing H, Geng Y, Wang X, Zhang Y, Peng L, Zhang $\mathrm{H}$ and Jiang B. p21-activated kinase 5 inhibits camptothecin-induced apoptosis in colorectal carcinoma cells. Tumour biology. 2010; 31:575-582.

71. Wong LE, Chen N, Karantza V and Minden A. The Pak4 protein kinase is required for oncogenic transformation of MDA-MB-231 breast cancer cells. Oncogenesis. 2013; $2: \mathrm{e} 50$.

72. Balasenthil S, Sahin AA, Barnes CJ, Wang RA, Pestell RG, Vadlamudi RK and Kumar R. p21-activated kinase-1 signaling mediates cyclin D1 expression in mammary epithelial and cancer cells. J Biol Chem. 2004; 279:14221428.

73. Menges CW, Sementino E, Talarchek J, Xu J, Chernoff J, Peterson JR and Testa JR. Group I p21-activated kinases (PAKs) promote tumor cell proliferation and survival through the AKT1 and Raf-MAPK pathways. Molecular cancer research. 2012; 10:1178-1188.

74. Arias-Romero LE, Villamar-Cruz O, Pacheco A, Kosoff R, Huang M, Muthuswamy SK and Chernoff J. A RacPak signaling pathway is essential for ErbB2-mediated transformation of human breast epithelial cancer cells. Oncogene. 2010; 29:5839-5849. 
75. Huynh N, Liu KH, Baldwin GS and He H. P21-activated kinase 1 stimulates colon cancer cell growth and migration/ invasion via ERK- and AKT-dependent pathways. Biochimica et biophysica acta. 2010; 1803:1106-1113.

76. Wang Z, Fu M, Wang L, Liu J, Li Y, Brakebusch C and Mei Q. p21-activated kinase 1 (PAK1) can promote ERK activation in a kinase-independent manner. J Biol Chem. 2013; 288:20093-20099.

77. Siu MK, Chan HY, Kong DS, Wong ES, Wong OG, Ngan HY, Tam KF, Zhang H, Li Z, Chan QK, Tsao SW, Stromblad S and Cheung AN. p21-activated kinase 4 regulates ovarian cancer cell proliferation, migration, and invasion and contributes to poor prognosis in patients. Proceedings of the National Academy of Sciences of the United States of America. 2010; 107:18622-18627.

78. Wang C, Li Y, Zhang H, Liu F, Cheng Z, Wang D, Wang G, $\mathrm{Xu} \mathrm{H}$, Zhao Y, Cao L and Li F. Oncogenic PAK4 regulates Smad2/3 axis involving gastric tumorigenesis. Oncogene. 2014; 33:3473-3484.

79. Goeckeler ZM, Masaracchia RA, Zeng Q, Chew TL, Gallagher P and Wysolmerski RB. Phosphorylation of myosin light chain kinase by $\mathrm{p} 21$-activated kinase PAK2. J Biol Chem. 2000; 275:18366-18374.

80. Dan C, Kelly A, Bernard O and Minden A. Cytoskeletal changes regulated by the PAK4 serine/threonine kinase are mediated by LIM kinase 1 and cofilin. J Biol Chem. 2001; 276:32115-32121.

81. Van Troys M, Huyck L, Leyman S, Dhaese S, Vandekerkhove J and Ampe C. Ins and outs of ADF/cofilin activity and regulation. Eur J Cell Biol. 2008; 87:649-667.

82. Vadlamudi RK, Li F, Barnes CJ, Bagheri-Yarmand R and Kumar R. p41-Arc subunit of human Arp2/3 complex is a p21-activated kinase-1-interacting substrate. EMBO Rep. 2004; 5:154-160.

83. Sells MA, Pfaff A and Chernoff J. Temporal and spatial distribution of activated Pak1 in fibroblasts. J Cell Biol. 2000; 151:1449-1458.

84. Dan C, Nath N, Liberto M and Minden A. PAK5, a new brain-specific kinase, promotes neurite outgrowth in N1E115 cells. Mol Cell Biol. 2002; 22:567-577.

85. Nayal A, Webb DJ, Brown CM, Schaefer EM, VicenteManzanares M and Horwitz AR. Paxillin phosphorylation at Ser273 localizes a GIT1-PIX-PAK complex and regulates adhesion and protrusion dynamics. J Cell Biol. 2006; 173:587-589.

86. Vadlamudi RK, Li F, Adam L, Nguyen D, Ohta Y, Stossel TP and Kumar R. Filamin is essential in actin cytoskeletal assembly mediated by p21-activated kinase 1 . Nat Cell Biol. 2002; 4:681-690.

87. Elloul S, Vaksman O, Stavnes HT, Trope CG, Davidson $\mathrm{B}$ and Reich R. Mesenchymal-to-epithelial transition determinants as characteristics of ovarian carcinoma effusions. Clin Exp Metastasis. 2010; 27:161-172.
88. Yang Z, Rayala S, Nguyen D, Vadlamudi RK, Chen S and Kumar R. Pak1 phosphorylation of snail, a master regulator of epithelial-to-mesenchyme transition, modulates snail's subcellular localization and functions. Cancer research. 2005; 65:3179-3184.

89. Fram S, King H, Sacks DB and Wells CM. A PAK6IQGAP1 complex promotes disassembly of cell-cell adhesions. Cellular and molecular life sciences. 2014; 71:2759-2773.

90. Morse EM, Sun X, Olberding JR, Ha BH, Boggon TJ and Calderwood DA. PAK6 targets to cell-cell adhesions through its $\mathrm{N}$-terminus in a Cdc42-dependent manner to drive epithelial colony escape. Journal of cell science. 2016; 129:380-393.

91. Selamat W, Tay PL, Baskaran Y and Manser E. The Cdc42 Effector Kinase PAK4 Localizes to Cell-Cell Junctions and Contributes to Establishing Cell Polarity. PloS one. 2015; 10:e0129634.

92. Rider L, Oladimeji P and Diakonova M. PAK1 regulates breast cancer cell invasion through secretion of matrix metalloproteinases in response to prolactin and threedimensional collagen IV. Mol Endocrinol. 2013; 27:10481064.

93. Goc A, Al-Azayzih A, Abdalla M, Al-Husein B, Kavuri S, Lee J, Moses K and Somanath PR. P21 activated kinase-1 (Pak1) promotes prostate tumor growth and microinvasion via inhibition of transforming growth factor beta expression and enhanced matrix metalloproteinase 9 secretion. J Biol Chem. 2013; 288:3025-3035.

94. Wells CM, Whale AD, Parsons M, Masters JR and Jones GE. PAK4: a pluripotent kinase that regulates prostate cancer cell adhesion. Journal of cell science. 2010; 123:1663-1673.

95. Kim TW, Kang YK, Park ZY, Kim YH, Hong SW, Oh SJ, Sohn HA, Yang SJ, Jang YJ, Lee DC, Kim SY, Yoo HS, Kim E, Yeom YI and Park KC. SH3RF2 functions as an oncogene by mediating PAK4 protein stability. Carcinogenesis. 2014; 35:624-634.

96. Wang XX, Cheng Q, Zhang SN, Qian HY, Wu JX, Tian H, Pei DS and Zheng JN. PAK5-Egr1-MMP2 signaling controls the migration and invasion in breast cancer cell. Tumour biology. 2013; 34:2721-2729.

97. Han ZX, Wang XX, Zhang SN, Wu JX, Qian HY, Wen YY, Tian H, Pei DS and Zheng JN. Downregulation of PAK5 inhibits glioma cell migration and invasion potentially through the PAK5-Egr1-MMP2 signaling pathway. Brain Tumor Pathol. 2014; 31:234-241.

98. Sato M, Matsuda Y, Wakai T, Kubota M, Osawa M, Fujimaki S, Sanpei A, Takamura M, Yamagiwa S and Aoyagi Y. P21-activated kinase-2 is a critical mediator of transforming growth factor-beta-induced hepatoma cell migration. J Gastroenterol Hepatol. 2013; 28:1047-1055.

99. Holderness Parker N, Donninger H, Birrer MJ and Leaner VD. p21-activated kinase 3 (PAK3) is an AP-1 regulated 
gene contributing to actin organisation and migration of transformed fibroblasts. PloS one. 2013; 8:e66892.

100. Srinivasan R, Zabuawala T, Huang H, Zhang J, Gulati P, Fernandez S, Karlo JC, Landreth GE, Leone G and Ostrowski MC. Erk1 and Erk2 regulate endothelial cell proliferation and migration during mouse embryonic angiogenesis. PloS one. 2009; 4:e8283.

101. Shalom-Barak T and Knaus UG. A p21-activated kinasecontrolled metabolic switch up-regulates phagocyte NADPH oxidase. J Biol Chem. 2002; 277:40659-40665.

102. Gururaj A, Barnes CJ, Vadlamudi RK and Kumar R. Regulation of phosphoglucomutase 1 phosphorylation and activity by a signaling kinase. Oncogene. 2004; 23:81188127.

103. Tan W, Palmby TR, Gavard J, Amornphimoltham P, Zheng $Y$ and Gutkind JS. An essential role for Rac1 in endothelial cell function and vascular development. FASEB journal. 2008; 22:1829-1838.

104. Siu MK, Wong ES, Chan HY, Kong DS, Woo NW, Tam KF, Ngan HY, Chan QK, Chan DC, Chan KY and Cheung AN. Differential expression and phosphorylation of Pak1 and Pak2 in ovarian cancer: effects on prognosis and cell invasion. International journal of cancer. 2010; 127:21-31.

105. Park J, Kim JM, Park JK, Huang S, Kwak SY, Ryu KA, Kong G, Park J and Koo BS. Association of p21-activated kinase-1 activity with aggressive tumor behavior and poor prognosis of head and neck cancer. Head \& neck. 2015; 37:953-963.

106. Gao C, Ma T, Pang L and Xie R. Activation of P21activated protein kinase 2 is an independent prognostic predictor for patients with gastric cancer. Diagnostic pathology. 2014; 9:55.

107. Ahn M, Yoder SM, Wang Z, Oh E, Ramalingam L, Tunduguru $\mathrm{R}$ and Thurmond DC. The p21-activated kinase (PAK1) is involved in diet-induced beta cell mass expansion and survival in mice and human islets. Diabetologia. 2016.

108. Begum A, Imoto I, Kozaki K, Tsuda H, Suzuki E, Amagasa $\mathrm{T}$ and Inazawa $\mathrm{J}$. Identification of PAK4 as a putative target gene for amplification within 19q13.12-q13.2 in oral squamous-cell carcinoma. Cancer Sci. 2009; 100:19081916.

109. Chen H, Miao J, Li H, Wang C, Li J, Zhu Y, Wang J, Wu X and Qiao H. Expression and prognostic significance of p21activated kinase 6 in hepatocellular carcinoma. The Journal of surgical research. 2014; 189:81-88.

110. Brown LA, Kalloger SE, Miller MA, Shih Ie M, McKinney SE, Santos JL, Swenerton K, Spellman PT, Gray J, Gilks $\mathrm{CB}$ and Huntsman DG. Amplification of 11q13 in ovarian carcinoma. Genes, chromosomes \& cancer. 2008; 47:481489.

111. Lundgren K, Holm K, Nordenskjold B, Borg A and Landberg G. Gene products of chromosome 11q and their association with CCND1 gene amplification and tamoxifen resistance in premenopausal breast cancer. Breast cancer research. 2008; 10:R81.

112. Karlsson E, Waltersson MA, Bostner J, Perez-Tenorio G, Olsson B, Hallbeck AL and Stal O. High-resolution genomic analysis of the 11q13 amplicon in breast cancers identifies synergy with 8p12 amplification, involving the mTOR targets S6K2 and 4EBP1. Genes, chromosomes \& cancer. 2011; 50:775-787.

113. Mahlamaki EH, Kauraniemi P, Monni O, Wolf M, Hautaniemi S and Kallioniemi A. High-resolution genomic and expression profiling reveals 105 putative amplification target genes in pancreatic cancer. Neoplasia. 2004; 6:432439.

114. Hu X, Guo J, Zheng L, Li C, Zheng TM, Tanyi JL, Liang S, Benedetto C, Mitidieri M, Katsaros D, Zhao X, Zhang Y, Huang $Q$ and Zhang L. The heterochronic microRNA let-7 inhibits cell motility by regulating the genes in the actin cytoskeleton pathway in breast cancer. Molecular cancer research. 2013; 11:240-250.

115. Zhang Y, Takahashi S, Tasaka A, Yoshima T, Ochi H and Chayama K. Involvement of microRNA-224 in cell proliferation, migration, invasion, and anti-apoptosis in hepatocellular carcinoma. J Gastroenterol Hepatol. 2013; 28:565-575.

116. Hou J, Lin L, Zhou W, Wang Z, Ding G, Dong Q, Qin L, Wu X, Zheng Y, Yang Y, Tian W, Zhang Q, Wang C, Zhang Q, Zhuang SM, Zheng L, et al. Identification of miRNomes in human liver and hepatocellular carcinoma reveals miR-199a/b-3p as therapeutic target for hepatocellular carcinoma. Cancer cell. 2011; 19:232-243.

117. Han J, Wang F, Yuan SQ, Guo Y, Zeng ZL, Li LR, Yang J, Wang DS, Liu MY, Zhao H, Liu KY, Liao JW, Zou QF and $\mathrm{Xu}$ RH. Reduced expression of $\mathrm{p} 21$-activated protein kinase 1 correlates with poor histological differentiation in pancreatic cancer. BMC cancer. 2014; 14:650.

118. Zhou W, Jubb AM, Lyle K, Xiao Q, Ong CC, Desai R, Fu L, Gnad F, Song Q, Haverty PM, Aust D, Grutzmann R, Romero M, Totpal K, Neve RM, Yan Y, et al. PAK1 mediates pancreatic cancer cell migration and resistance to MET inhibition. The Journal of pathology. 2014; 234:502513.

119. Jagadeeshan S, Krishnamoorthy YR, Singhal M, Subramanian A, Mavuluri J, Lakshmi A, Roshini A, Baskar G, Ravi M, Joseph LD, Sadasivan K, Krishnan A, Nair AS, Venkatraman G and Rayala SK. Transcriptional regulation of fibronectin by p21-activated kinase-1 modulates pancreatic tumorigenesis. Oncogene. 2015; 34:455-464.

120. Yeo D, He H, Patel O, Lowy AM, Baldwin GS and Nikfarjam M. FRAX597, a PAK1 inhibitor, synergistically reduces pancreatic cancer growth when combined with gemcitabine. BMC cancer. 2016; 16:24.

121. Chen S, Auletta T, Dovirak O, Hutter C, Kuntz K, El-ftesi S, Kendall J, Han H, Von Hoff DD, Ashfaq R, Maitra A, Iacobuzio-Donahue CA, Hruban RH and Lucito R. Copy number alterations in pancreatic cancer identify recurrent PAK4 amplification. Cancer Biol Ther. 2008; 7:1793-1802. 
122. Kimmelman AC, Hezel AF, Aguirre AJ, Zheng H, Paik JH, Ying H, Chu GC, Zhang JX, Sahin E, Yeo G, Ponugoti A, Nabioullin R, Deroo S, Yang S, Wang X, McGrath JP, et al. Genomic alterations link Rho family of GTPases to the highly invasive phenotype of pancreas cancer. Proceedings of the National Academy of Sciences of the United States of America. 2008; 105:19372-19377.

123. Tyagi N, Bhardwaj A, Singh AP, McClellan S, Carter JE and Singh S. p-21 activated kinase 4 promotes proliferation and survival of pancreatic cancer cells through AKT- and ERK-dependent activation of NF-kappaB pathway. Oncotarget. 2014; 5:8778-8789. doi: 10.18632/ oncotarget.2398.

124. Tu HF, Chang KW, Chiang WF, Liu CJ, Yu EH, Liu ST and Lin SC. The frequent co-expression of the oncogenes PIK3CA and PAK1 in oral carcinomas. Oral oncology. 2011; 47:211-216.

125. Higuchi M, Onishi K, Kikuchi C and Gotoh Y. Scaffolding function of PAK in the PDK1-Akt pathway. Nat Cell Biol. 2008; 10:1356-1364.

126. Badolia R, Manne BK, Dangelmaier C, Chernoff J and Kunapuli SP. Gq-mediated Akt translocation to the membrane: a novel PIP3-independent mechanism in platelets. Blood. 2015; 125:175-184.

127. Yang Y, Du J, Hu Z, Liu J, Tian Y, Zhu Y, Wang L and Gu L. Activation of Rac1-PI3K/Akt is required for epidermal growth factor-induced PAK1 activation and cell migration in MDA-MB-231 breast cancer cells. Journal of biomedical research. 2011; 25:237-245.

128. Chow HY, Jubb AM, Koch JN, Jaffer ZM, Stepanova D, Campbell DA, Duron SG, O'Farrell M, Cai KQ, KleinSzanto AJ, Gutkind JS, Hoeflich KP and Chernoff J. p21Activated kinase 1 is required for efficient tumor formation and progression in a Ras-mediated skin cancer model. Cancer research. 2012; 72:5966-5975.

129. He LF, Xu HW, Chen M, Xian ZR, Wen XF, Chen MN, $\mathrm{Du} \mathrm{CW}$, Huang WH, Wu JD, Zhang GJ. ActivatedPAK4 predicts worse prognosis in breast cancer and promotes tumorigenesis through activation of PI3K/AKT signaling. Oncotarget. 2016 February 17. doi: 10.18632/ oncotarget.7466. [Epub ahead of print].

130. Fu X, Feng J, Zeng D, Ding Y, Yu C and Yang B. PAK4 confers cisplatin resistance in gastric cancer cells via $\mathrm{PI} 3 \mathrm{~K} /$ Akt- and MEK/Erk-dependent pathways. Bioscience reports. 2014.

131. Moore MJ, Goldstein D, Hamm J, Figer A, Hecht JR, Gallinger S, Au HJ, Murawa P, Walde D, Wolff RA, Campos D, Lim R, Ding K, Clark G, Voskoglou-Nomikos T, Ptasynski M, et al. Erlotinib plus gemcitabine compared with gemcitabine alone in patients with advanced pancreatic cancer: a phase III trial of the National Cancer Institute of Canada Clinical Trials Group. Journal of clinical oncology. 2007; 25:1960-1966.

132. Van Cutsem E, van de Velde H, Karasek P, Oettle H, Vervenne WL, Szawlowski A, Schoffski P, Post S, Verslype
C, Neumann H, Safran H, Humblet Y, Perez Ruixo J, Ma $\mathrm{Y}$ and Von Hoff D. Phase III trial of gemcitabine plus tipifarnib compared with gemcitabine plus placebo in advanced pancreatic cancer. Journal of clinical oncology. 2004; 22:1430-1438.

133. Patgiri A, Yadav KK, Arora PS and Bar-Sagi D. An orthosteric inhibitor of the Ras-Sos interaction. Nature chemical biology. 2011; 7:585-587.

134. Ostrem JM and Shokat KM. Direct small-molecule inhibitors of KRAS: from structural insights to mechanismbased design. Nature reviews Drug discovery. 2016.

135. Gao HZ, Kobayashi K, Tabata A, Tsuge H, Iijima M, Yasuda T, Kalkanoglu HS, Dursun A, Tokatli A, Coskun T, Trefz FK, Skladal D, Mandel H, Seidel J, Kodama S, Shirane S, et al. Identification of 16 novel mutations in the argininosuccinate synthetase gene and genotype-phenotype correlation in 38 classical citrullinemia patients. Human mutation. 2003; 22:24-34.

136. Ayala G, Yan J, Li R, Ding Y, Thompson TC, Mims MP, Hayes TG, MacDonnell V, Lynch RG, Frolov A, Miles BJ, Wheeler TM, Harper JW, Tsai MJ, Ittmann MM and Kadmon D. Bortezomib-mediated inhibition of steroid receptor coactivator-3 degradation leads to activated Akt. Clinical cancer research. 2008; 14:7511-7518.

137. Cao P, Maira SM, Garcia-Echeverria C and Hedley DW. Activity of a novel, dual PI3-kinase/mTor inhibitor NVPBEZ235 against primary human pancreatic cancers grown as orthotopic xenografts. British journal of cancer. 2009; 100:1267-1276.

138. Sarker D, Ang JE, Baird R, Kristeleit R, Shah K, Moreno V, Clarke PA, Raynaud FI, Levy G, Ware JA, Mazina K, Lin R, Wu J, Fredrickson J, Spoerke JM, Lackner MR, et al. First-in-human phase I study of pictilisib (GDC-0941), a potent pan-class I phosphatidylinositol-3-kinase (PI3K) inhibitor, in patients with advanced solid tumors. Clinical cancer research. 2015; 21:77-86.

139. Alagesan B, Contino G, Guimaraes AR, Corcoran RB, Deshpande V, Wojtkiewicz GR, Hezel AF, Wong KK, Loda M, Weissleder R, Benes C, Engelman JA and Bardeesy N. Combined MEK and PI3K inhibition in a mouse model of pancreatic cancer. Clinical cancer research. 2015; 21:396404.

140. Collisson EA, Trejo CL, Silva JM, Gu S, Korkola JE, Heiser LM, Charles RP, Rabinovich BA, Hann B, Dankort D, Spellman PT, Phillips WA, Gray JW and McMahon M. A central role for $\mathrm{RAF} \longrightarrow \mathrm{MEK} \longrightarrow \mathrm{ERK}$ signaling in the genesis of pancreatic ductal adenocarcinoma. Cancer discovery. 2012; 2:685-693.

141. Rudolph J, Crawford JJ, Hoeflich KP and Chernoff J. p21activated kinase inhibitors. The Enzymes. 2013; 34 Pt. B:157-180.

142. Crawford JJ, Hoeflich KP and Rudolph J. p21-Activated kinase inhibitors: a patent review. Expert opinion on therapeutic patents. 2012; 22:293-310. 
143. Murray BW, Guo C, Piraino J, Westwick JK, Zhang C, Lamerdin J, Dagostino E, Knighton D, Loi CM, Zager M, Kraynov E, Popoff I, Christensen JG, Martinez R, Kephart SE, Marakovits J, et al. Small-molecule p21activated kinase inhibitor PF-3758309 is a potent inhibitor of oncogenic signaling and tumor growth. Proceedings of the National Academy of Sciences of the United States of America. 2010; 107:9446-9451.

144. Rose L BA, Darang S, Gallo J, Goldman J, Qang D, Mileshkin L, Eckhardt A. Abstract A177; Phase 1 dose esclation, safety, pharmacokinetic and pharmacodynamic study of single agent PF-03758309, an oral PAK inhibitor, in patients with advanced solid tumours. Molecular cancer therapeutics. 2011.

145. Azmi AS. Novel PAK4 inhibitors for pancreatic cancer therapy. J CLin Oncol 32 (suppl 3; abstr 233). 2014.

146. Moon SU, Kim JW, Sung JH, Kang MH, Kim SH, Chang H, Lee JO, Kim YJ, Lee KW, Kim JH, Bang SM and Lee JS. p21-Activated Kinase 4 (PAK4) as a Predictive Marker of Gemcitabine Sensitivity in Pancreatic Cancer Cell Lines. Cancer research and treatment. 2015; 47:501-508.

147. Chapman PB. Mechanisms of resistance to RAF inhibition in melanomas harboring a BRAF mutation. American Society of Clinical Oncology educational book / ASCO American Society of Clinical Oncology Meeting. 2013.

148. Feldman RI, Wu JM, Polokoff MA, Kochanny MJ, Dinter $\mathrm{H}$, Zhu D, Biroc SL, Alicke B, Bryant J, Yuan S, Buckman BO, Lentz D, Ferrer M, Whitlow M, Adler M, Finster S, et al. Novel small molecule inhibitors of 3-phosphoinositidedependent kinase-1. J Biol Chem. 2005; 280:19867-19874.

149. Mukherjee B, Tomimatsu N, Amancherla K, Camacho $\mathrm{CV}$, Pichamoorthy $\mathrm{N}$ and Burma S. The dual PI3K/mTOR inhibitor NVP-BEZ235 is a potent inhibitor of ATM- and DNA-PKCs-mediated DNA damage responses. Neoplasia. 2012; 14:34-43.

150. Hirai H, Sootome H, Nakatsuru Y, Miyama K, Taguchi S, Tsujioka K, Ueno Y, Hatch H, Majumder PK, Pan BS and Kotani H. MK-2206, an allosteric Akt inhibitor, enhances antitumor efficacy by standard chemotherapeutic agents or molecular targeted drugs in vitro and in vivo. Molecular cancer therapeutics. 2010; 9:1956-1967.
151. Holt SV, Logie A, Odedra R, Heier A, Heaton SP, Alferez D, Davies BR, Wilkinson RW and Smith PD. The MEK1/2 inhibitor, selumetinib (AZD6244; ARRY-142886), enhances anti-tumour efficacy when combined with conventional chemotherapeutic agents in human tumour xenograft models. British journal of cancer. 2012; 106:858866.

152. Gilmartin AG, Bleam MR, Groy A, Moss KG, Minthorn EA, Kulkarni SG, Rominger CM, Erskine S, Fisher KE, Yang J, Zappacosta F, Annan R, Sutton D and Laquerre SG. GSK1120212 (JTP-74057) is an inhibitor of MEK activity and activation with favorable pharmacokinetic properties for sustained in vivo pathway inhibition. Clinical cancer research. 2011; 17:989-1000.

153. Rhodes N, Heerding DA, Duckett DR, Eberwein DJ, Knick VB, Lansing TJ, McConnell RT, Gilmer TM, Zhang SY, Robell K, Kahana JA, Geske RS, Kleymenova EV, Choudhry AE, Lai Z, Leber JD, et al. Characterization of an Akt kinase inhibitor with potent pharmacodynamic and antitumor activity. Cancer research. 2008; 68:2366-2374.

154. Licciulli S, Maksimoska J, Zhou C, Troutman S, Kota S, Liu Q, Duron S, Campbell D, Chernoff J, Field J, Marmorstein $\mathrm{R}$ and Kissil JL. FRAX597, a small molecule inhibitor of the p21-activated kinases, inhibits tumorigenesis of neurofibromatosis type 2 (NF2)-associated Schwannomas. J Biol Chem. 2013; 288:29105-29114.

155. Gharbi SI, Zvelebil MJ, Shuttleworth SJ, Hancox T, Saghir N, Timms JF and Waterfield MD. Exploring the specificity of the PI3K family inhibitor LY294002. The Biochemical journal. 2007; 404:15-21.

156. Maira SM, Pecchi S, Huang A, Burger M, Knapp M, Sterker D, Schnell C, Guthy D, Nagel T, Wiesmann M, Brachmann S, Fritsch C, Dorsch M, Chene P, Shoemaker $\mathrm{K}$, De Pover A, et al. Identification and characterization of NVP-BKM120, an orally available pan-class I PI3-kinase inhibitor. Molecular cancer therapeutics. 2012; 11:317-328. 